\title{
The initiation and development of combustion under cold idling conditions using a glow plug in diesel engines
}

\author{
Q Li, P J Shayler, M McGhee, A LaRocca \\ University of Nottingham, UK \\ Corresponding Author: P J Shayler, Email: paul.shayler@nottingham.ac.uk
}

\begin{abstract}
Factors determining the success or failure of combustion initiation using a glow plug have been investigated through experimental work on a single cylinder, common rail diesel engine with a geometric compression ratio of 15.5 , and a quiescent combustion bomb with optical access. A glow plug was required to avoid engine misfires when bulk gas temperature at the start of injection was less than $413^{\circ} \mathrm{C}$. The distance between the glow plug and the spray edge, glow plug temperature and bulk gas temperature were important factors in meeting two requirements for successful ignition: a minimum local temperature of $413^{\circ} \mathrm{C}$, and a minimum air/fuel vapour equivalence ratio of 0.15-0.35.
\end{abstract}

\section{Introduction}

High speed, DI diesel engines with common rail fuel injection systems are widely used in light duty automotive applications for reasons which include good fuel economy and low $\mathrm{CO}_{2}$ emissions. Improving engine cold start and the early seconds of warm-up continues to attract attention, especially for low ambient temperature conditions at which potential problems include poor cycle by cycle combustion stability[1, 2], increased exhaust emissions including HC, CO and PM [3-5], long cranking periods and noise. These can be exacerbated by the use of lower compression ratios $[6,7]$ for light duty engines in recent years to improve the $\mathrm{NO}_{x} / \mathrm{PM}$ trade-off at part load and achieve higher specific torque and power at full load by using higher boost pressures [8, 9]. The trend has seen compression ratios reduce from around 19:1 in the 1980's [10] to now typically 16:1 and as low as 14:1 in the case of Mazda's Skyactiv diesel engine [11]. Glow plugs have long been used as a cold start aid, and have proven effective in raising work output and minimising misfiring [12, 13]. Post start idle stability is likely to deteriorate as compression ratio is reduced and MacMillan et al. [14] demonstrated that a combination of using multiple pilot injections and a high glow plug 
operating temperature was effective in minimising cycle by cycle variations at a low compression ratio of (15.5:1).

Details of the initiation and early development of combustion in a firing engine cylinder are difficult to unravel from cylinder pressure measurements because of the small heat release involved. Commonly, optical techniques are employed which require either engine modifications to provide optical access to the combustion system or as here, the use of a combustion bomb. Optical studies of the initiation of combustion aided by a glow plug have been reported in several publications [7, 15-17]. These have shown that the site of initiation is in the vicinity of the glow plug surface and combustion spreads into one or both sprays nearest to the glow plug before the remaining sprays ignite. Both glow plug temperature and the proximity of the spray have been identified as important influencing cycle by cycle stability of indicated work output. The impact of spray angle and injector orientation on combustion characteristics has been studied by Pacaud et al. [7], for a diesel engine with a low compression ratio $(13.7: 1)$ and test temperatures down to $-20^{\circ} \mathrm{C}$. They observed that ignition delay could be reduced by increasing spray angle and rotating the injector to change the spray direction by $-20^{\circ}$, and concluded that reductions in glow plug tip to spray distance shortened the ignition delay and increased the potential for successful auto-ignition. MacMillan et al. [14] investigated the impact of glow plug temperature on the cycle by cycle stability of work output of a common rail diesel engine at low compression ratio. They showed that cold idle stability could be greatly improved through the use of ceramic glow plugs to raise glow plug temperature. This had the effect of reducing ignition delay and increasing the peak rate of heat release as glow plug temperature increased. In complementary studies, McGhee et al. $[1,10]$ investigated a range of factors which influence the early stage of diesel spray combustion in a quiescent optical vessel and showed that glow plug temperature and number of pilot injections have the strongest impact on initiation of combustion. The importance of glow plug temperature and glow-plug- to- spray distance was also recognised by Pastor et al. [18, 19], who suggest these control the initiation of pilot combustion on the nearest sprays which in turn initiates combustion of a subsequent main injection of fuel. Combustion of the first spray propagates to enflame the other sprays, a process aided by the turbulent motion generated by the injection event. They concluded that ignition and combustion in low-temperature conditions starts near the glow plug due to the increased temperature and fuel vapour mass, improving IMEP and combustion stability [20]. Broatch et al. [21] investigated the minimum charge temperature required for autoignition unaided by a glow plug and observed this to be $415^{\circ} \mathrm{C}$ before the start of injection. This is significantly higher than the predicted value of $387^{\circ} \mathrm{C}$ reported by Pacaud et al [7]. 
The investigations presented in this paper were undertaken to clarify requirements for the successful initiation and development of combustion. Of particular interest has been the relationship between glow plug temperature and the distance between the glow plug and the nearest adjacent spray for successful initiation. The site of the initial luminous emissions associated with the first high temperature reactions has been identified and how this relates to local temperature and mixture equivalence ratio has been explored. Three lines of investigation have been pursued: the first has explored the influence of the glow plug on heat release and cycle by cycle work output of a single cylinder diesel engine on start-up. The second has made use of a quiescent combustion bomb to explore conditions for successful combustion initiation using high speed video. The third has made use of the CFD code ANSYS Fluent 14.0 to investigate vapour generation and local equivalence ratio at the site of initiation.

\section{Single Cylinder Engine Investigations}

The aim of the tests reported in this section was to establish the influence of the glow plug on combustion. The range of temperatures covered spans the transition between requiring and not requiring the aid of the glow plug to achieve successful initiation of combustion. The single cylinder engine and test facility have been used in previous investigations of cold start and cold idling behaviour [1, 2, 6, 22]. The engine has a swept volume of $550 \mathrm{~cm}^{3}$ and a geometric compression ratio of 15.5:1. Carcal 740-B5-A diesel fuel was used in the engine tests and the optical studies, properties are given in Table $\mathbf{1 .}$

Table 1 Fuel Properties

\begin{tabular}{|c|c|c|c|c|c|}
\hline Property & Unit & $\begin{array}{c}\text { Spec } \\
\text { (Min) }\end{array}$ & $\begin{array}{c}\text { Spec } \\
\text { (Max) }\end{array}$ & Result & Method \\
\hline Cetane Number & & 52 & 54 & 54 & $\begin{array}{c}\text { ASME } \\
\text { D613 }\end{array}$ \\
\hline Cetane Index & & 50 & & 54.7 & $\begin{array}{c}\text { ASME } \\
\text { D4737 }\end{array}$ \\
\hline Density at 15ㅇ & $\mathrm{g} / \mathrm{ml}$ & 0.833 & 0.837 & 0.8331 & $\begin{array}{c}\text { ASME } \\
\text { D4052 }\end{array}$ \\
\hline Viscosity at 40ำ & $\mathrm{mm} / \mathrm{sec}$ & 2.3 & 3.3 & 2.6 & $\begin{array}{c}\text { ASME } \\
\text { D445 }\end{array}$ \\
\hline $\begin{array}{c}\text { Gross Calorific } \\
\text { Value }\end{array}$ & $\mathrm{MJ} / \mathrm{kg}$ & & & 44.58 & $\mathrm{IP12}$ \\
\hline $\begin{array}{c}\text { Net Calorific } \\
\text { Value }\end{array}$ & $\mathrm{MJ} / \mathrm{kg}$ & & & 41.73 & $\mathrm{IP12}$ \\
\hline
\end{tabular}

The tests were carried out with a metallic glow plug installed in the engine. The surface temperature of the glow plug in still air was measured to stabilise at $850^{\circ} \mathrm{C}$. In preparation for a test, the engine would be force-cooled to a uniform target temperature by circulating chilled 
coolant through the cylinder head and block. The fuel tank, fuel rail and injectors of the fuel injection system were insulated and chilled to the same target temperature. Engine-out coolant temperature was used as the reference test temperature. The air intake path was also insulated and chilled with the same coolant. An insulated 80 litre plenum incorporating a coolant-to-air heat exchanger was positioned just upstream of the intake manifold. This provided a large reservoir of air chilled to test temperature. During a test, intake air temperature was constant to within $1 / 2{ }^{\circ} \mathrm{C}$ as measured using a K-type thermocouple in the intake manifold.

Once target temperature conditions were established, a standard test procedure was followed. The aim was to achieve consistency of test conditions in the combustion system relevant to cold starts and idling, not to mimic the entire cold start process from key-on. To this end, the glow plug was powered on and the engine was motored for 15 engine cycles before enabling fuel injection. These initial cycles allowed a target speed and fuel rail pressure to be established before enabling fuel injection. Fuel injection was initiated on cycle 16 and continued for 40 consecutive cycles after which the test was ended. Post- test, the engine was motored for two minutes to draw purge air through the cylinder before cold soaking the engine in preparation for the next test. Generally, tests at the same conditions were repeated three times. Fully-warm engine conditioning tests were run daily to condition the engine and maintain repeatable cylinder conditions for subsequent tests. Although tests were continued for 40 firing cycles, the ensemble averaging of data was restricted to the first 10 of these. Over a larger number of cycles, the effects of surface temperature and fuel accumulation in the combustion system are increasingly significant. The extension of the test run aided the detection of any test problems and contributed to conditioning the engine for later tests.

The influence of fuel injection strategy and glow plug temperature on cycle by cycle variations in work output of the engine was reported in [1]. In this current study, engine tests were carried out using a fixed injection strategy to show the influence of the glow plug on net heat release and IMEP at three test temperatures $\left(3^{\circ} \mathrm{C}, 6^{\circ} \mathrm{C}\right.$ and $9^{\circ} \mathrm{C}$.) These straddle the $6^{\circ} \mathrm{C}$ value below which the use of the glow plug is necessary if early firing cycles are to be achieved whilst the range is narrow enough to allow the same fuel injection strategy to be used across the set of tests. Combustion cycle-by-cycle stability under cold idling conditions has been shown to be improved by using up to four pilot injections [2, 22], although this reduces the proportion of the total fuel delivered in the main injection which can make idle speed control through fuelling adjustments more difficult. At the mildly cold test temperatures used in the work reported here, an injection strategy combining twin pilots and a main provides an appropriate compromise. The demanded fuel mass of each pilot injection was 
$2 \mathrm{mg}$, followed by a main injection of $6 \mathrm{mg}$, giving a total fuel demand of $10 \mathrm{mg}$. The start-ofinjection timings were $20^{\circ}, 14^{\circ}$ and $8^{\circ} \mathrm{CA}$ BTDC, respectively for the first and second pilots and the main. All the tests have been carried out at a constant engine speed to facilitate direct comparisons of test results. The target speed of $1000 \mathrm{r} / \mathrm{min}$ is typical of initial idling speeds after start up at low temperatures, and more likely than lower speeds to exhibit high levels of cycle by cycle variation in the development of combustion [14, 22, 23]. For modern automotive diesel engines with lower compression ratios than older designs, this poor idling quality can be a more serious problem than achieving first-fire at cranking speeds.

Cylinder pressure was recorded as a function of crank angle throughout the test period and post-processed to find cycle by cycle values of the gross IMEP produced over the compression and expansion strokes of the cycle from

$I M E P g r o s s=\frac{\int_{B D C_{\text {intake }}}^{B D C_{\text {expansion }}} p d V}{V_{S}}$

The net heat release rate $\frac{d Q_{n e t}}{d \theta}$ has been determined from the same pressure data and knowledge of the cylinder volume above the piston at each crank angle. Following Heywood [24],

$\frac{d Q_{n e t}}{d \theta}=\frac{\gamma}{\gamma-1} p \frac{d V}{d \theta}+\frac{1}{\gamma-1} V \frac{d p}{d \theta}$

In this, the ratio of specific heats has been taken to be a function of bulk gas temperature only, as described by Brunt and Platts [25, 26]:

$\gamma=1.44-\left(1.2 \times 10^{-4} T\right)+\left(1 \times 10^{-8} T^{2}\right)$

The temperature at the end of compression, at the timing of the start of the main injection, was calculated assuming the charge temperature was equal to the intake air temperature at the start of the compression, the compression process was polytropic and finally that the charge behaved as a perfect gas. The polytropic index was determined from log plots of pressure versus volume.

At each test temperature, tests were repeated with the glow plug on or off. For each test, the data for the net heat release rate were ensemble averaged over the first 10 cycles. The results are presented in Figure 1. The glow plug clearly influences net heat release rate at the three temperatures, producing a strong premix spike and a strong diffusion burn. With the glow plug switched off, heat release is zero or rises weakly without any initial spike. From the second cycle onwards, gross IMEP values were flat. At $3^{\circ} \mathrm{C}$ and $6^{\circ} \mathrm{C}$, IMEP was negative 
or very close to zero. Only the IMEPg values for $9^{\circ} \mathrm{C}$ were positive, but still low at around 1 bar. Generally, this would be too low to overcome engine friction and raise engine speed from a cranking condition to a stable idle in a satisfactorily short time.

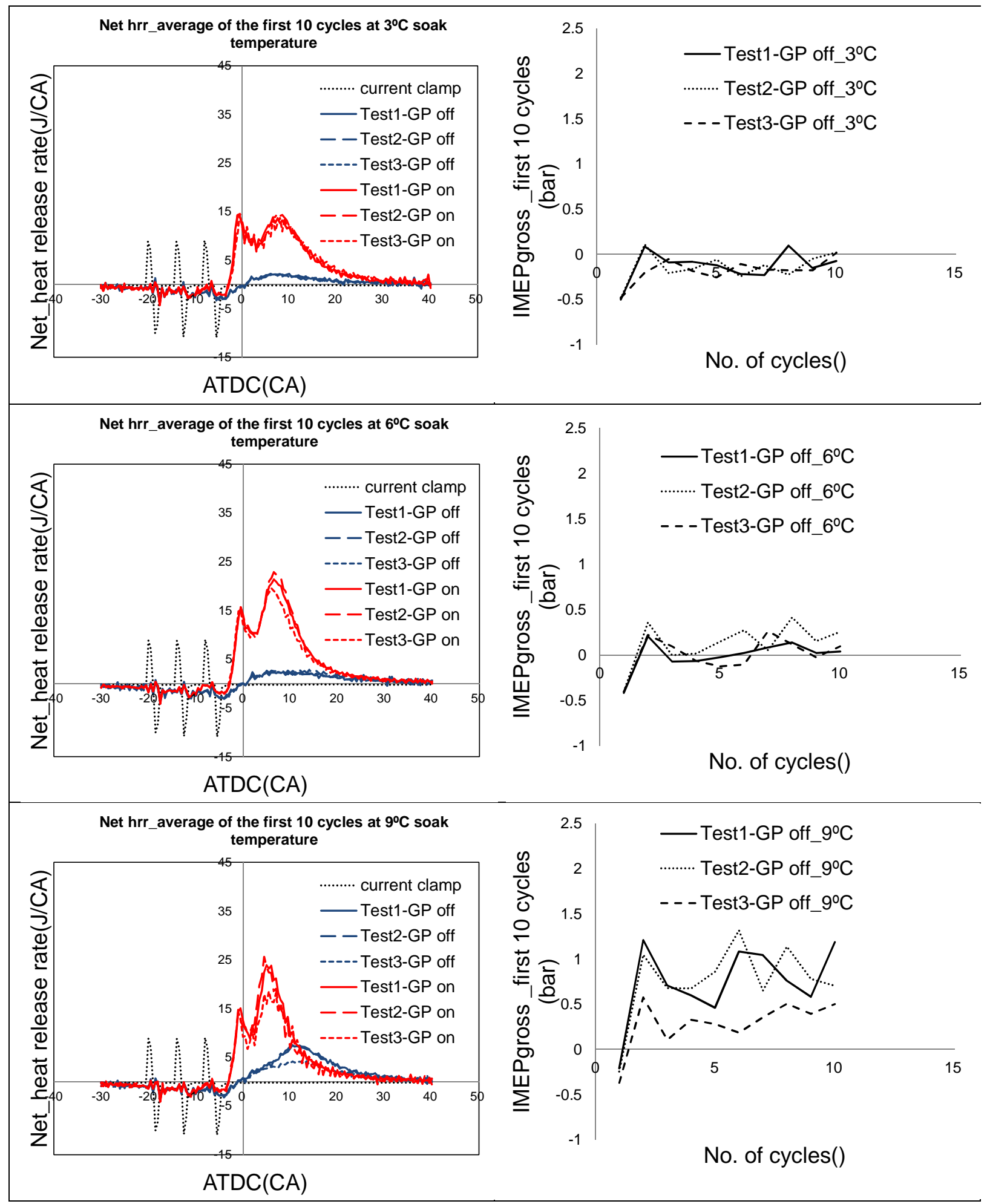

Figure 1: Averaged net heat release rate and IMEPgross over the first 10 cycles; Injection strategy: $(2,2,6) \mathrm{mg}$ with $6 \circ$ CA separation at injection timing $\left(-20^{\circ},-14^{\circ},-8 \circ\right)$ after TDC, $1000 \mathrm{r} / \mathrm{min}$ engine speed 
The results shown in Figure 1 illustrate that the glow plug influences more than initiation, given that, at $9^{\circ} \mathrm{C}$, work output was positive with the glow plug off but the development of heat release was weak. In Figure 2, the influence of the glow plug can be seen to extend across a range of test temperatures, affecting both the cumulative heat release and the gross IMEP. In Figure 2 (a), the cumulative heat release is higher with the glow plug switched on at all the temperatures covered. The advantage diminishes as test temperature is raised. During the period the tests were carried out, laboratory ambient set the upper limit on the initial temperature of the engine to be $17^{\circ} \mathrm{C}$, but extrapolation indicates the benefit of the glow plug persists up to temperatures around $20^{\circ} \mathrm{C}$. This is considerably higher than the temperature of $\sim 8^{\circ} \mathrm{C}$ at which reliable autoignition can be achieved without the glow plug. The ratio of cumulative heat release values for the glow plug off and on values given in Figure 2 (b) increases steadily to between 0.7 and 0.8 at the highest test temperature $\left(17^{\circ} \mathrm{C}\right)$, from close to zero at $\sim 4^{\circ} \mathrm{C}$. At lower temperatures, the glow plug was required to achieve reliable initiation and detectable heat release. The cycle-by-cycle variations in gross IMEP and cumulative heat release are represented by the standard deviations given in Figure 2 (c) and Figure 2 (d) respectively. Across the temperature range covered, with the glow plug switched on, the standard deviation of the gross IMEP is substantially lower, by up to half of that with the glow plug off. The benefit is far less clear in the standard deviation of cumulative heat release for temperatures below $8^{\circ} \mathrm{C}$, when most variation arises in the later stages of the burn.

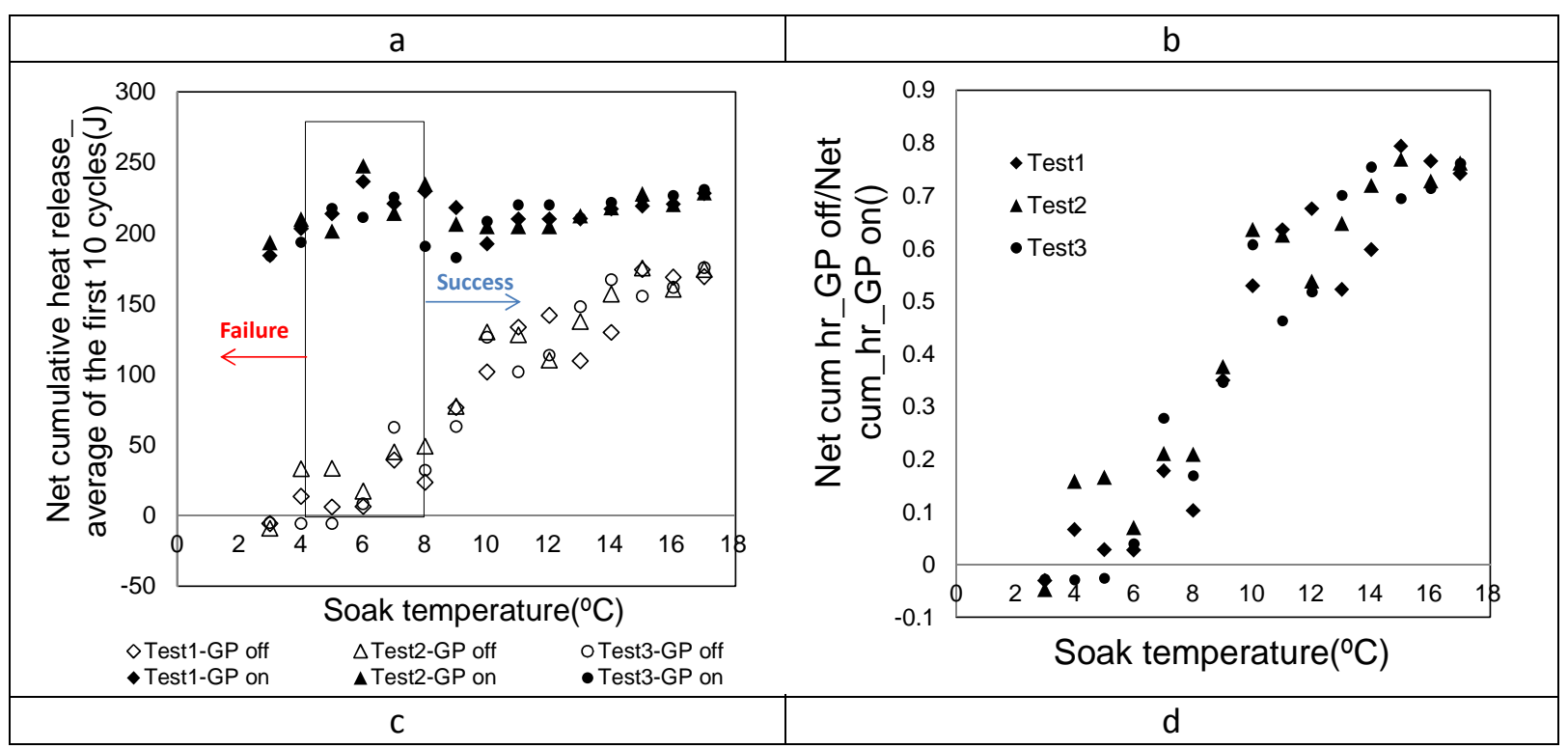




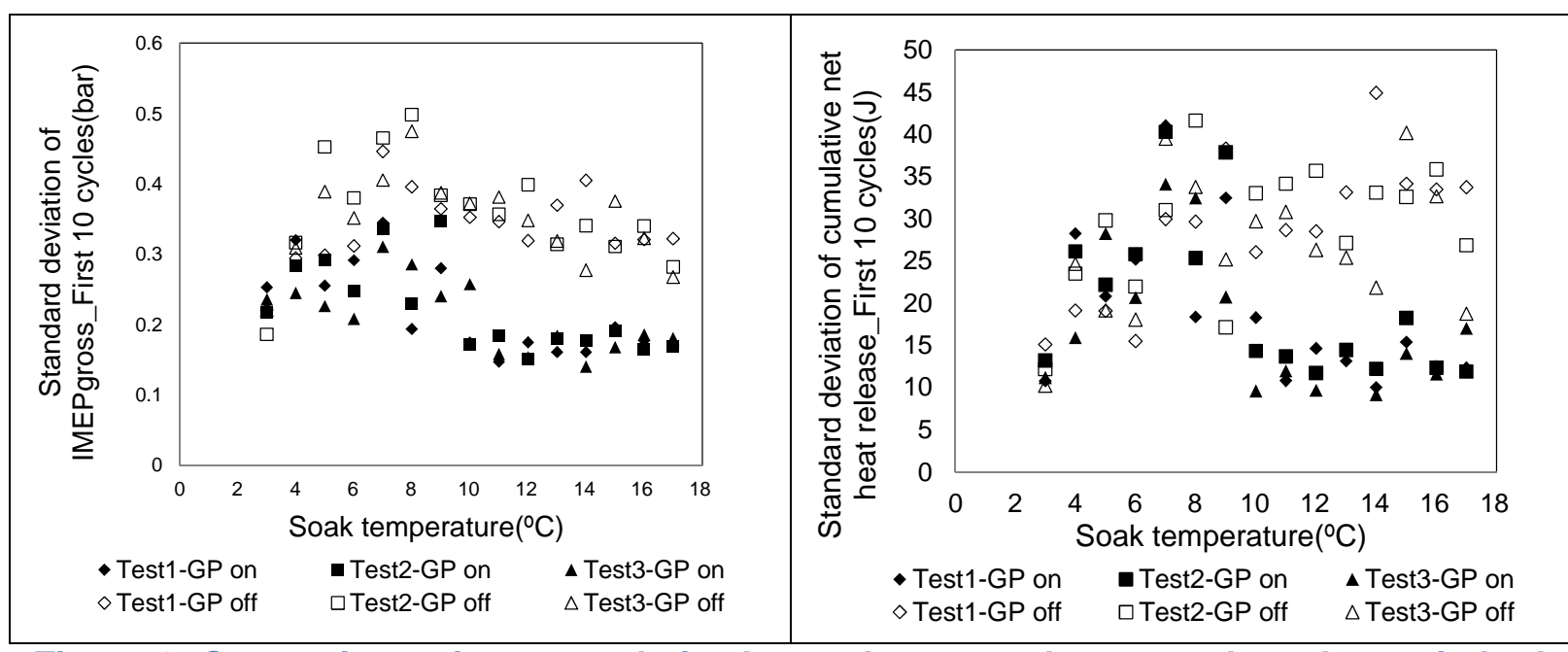

Figure 2: Comparison of net cumulative heat release rate between glow plug switched on and off (a); Ratio of cumulative heat release rate with glow plug switched off to that switched on (b); Standard deviation of IMEPgross (c) and cumulative heat release (d); Injection strategy: $(2,2,6) \mathrm{mg}$ with $6^{\circ} \mathrm{CA}$ separation at injection timing $\left(-20^{\circ},-14 \circ,-8^{\circ}\right)$ after TDC, $1000 \mathrm{r} / \mathrm{min}$ engine speed

At test temperatures above $8^{\circ} \mathrm{C}$, autoignition and self-sustaining combustion were reliably achieved without the glow plug although using the glow plug raised cumulative heat release and gross IMEP and reduced standard deviations up to projected test temperatures of $20^{\circ} \mathrm{C}$. At temperatures below $4^{\circ} \mathrm{C}$, there was no measurable heat release without the aid of the glow plug. The results suggest that at test temperatures between $4^{\circ} \mathrm{C}$ and $8^{\circ} \mathrm{C}$, the charge temperature at the time of fuel injection reaches the critical value required to achieving selfsustaining combustion. The critical temperature is dictated by the cylinder volume and temperature at the start of compression, the cylinder volume at the start of the main injection, and the polytropic index of the compression process.

The effective start of compression was taken to be the point at which cylinder pressure begins to follow the polytropic compression line on logarithmic plots of cylinder pressure versus cylinder volume. The charge temperature is assumed to be equal to the intake air temperature at this point. The effective compression ratio was taken to be the ratio of the volume at this point to the volume at the start of main injection. The effective compression ratio determined in this way was 13.8:1, which is lower that the geometric compression ratio of 15.5:1, and higher than the compression ratio value (13.3:1) calculated using the volume at the point of inlet valve closing, which occurs at $37^{\circ} \mathrm{CA}$ after BDC. The polytropic index (n) of the compression process was determined at a motored engine speed of $1000 \mathrm{r} / \mathrm{min}$ from $\log \mathrm{P}$ - $\log \mathrm{V}$ plots for a range of test temperatures. The validity of assuming the process was polytropic was confirmed by the linearity of the plotted process lines. This gives a constant value of the index for a given compression. The variation of the index with test temperature is shown in Figure 3 (a). The index falls slightly with increasing test temperature as gas heat 
transfer losses reduce. This lowers the ratio of final to initial temperatures, but the reduction in the ratio is offset by the rise in the initial (ambient) temperature with the net result that the temperature at the time of injection is approximately constant and given by

$$
T=T_{a}(\text { Compression ratio })^{n-1}
$$

As illustrated in Figure 3 (b), the critical temperature for self-sustaining combustion is between $410^{\circ} \mathrm{C}$ and $416^{\circ} \mathrm{C}$ and taken here to be the average of these, $413^{\circ} \mathrm{C}$. Assuming this critical temperature is independent of compression ratios and ambient temperatures, the band separating success and failure of combustion is shown in Figure 3 (c) for a range of effective compression ratios and ambient temperatures.

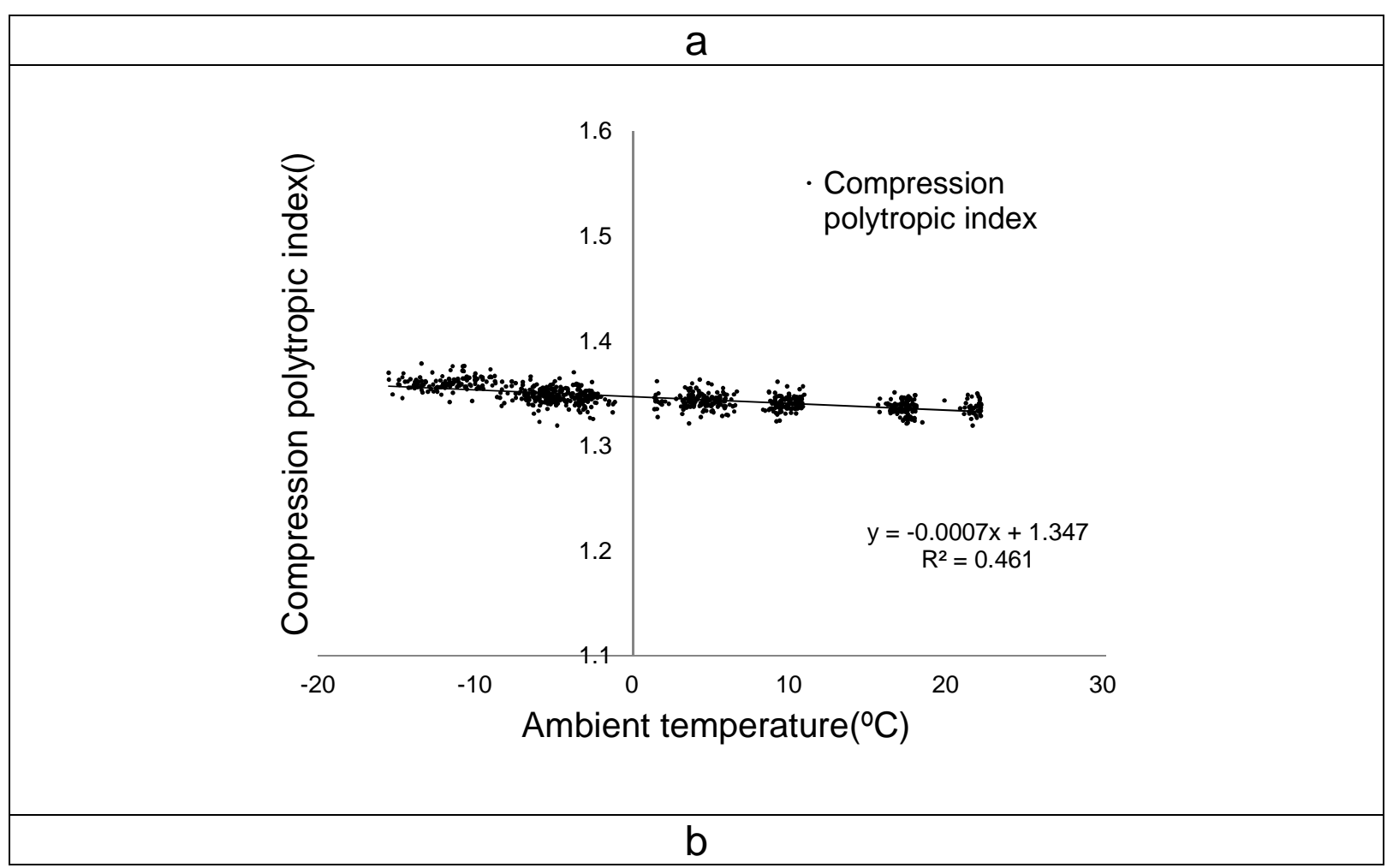




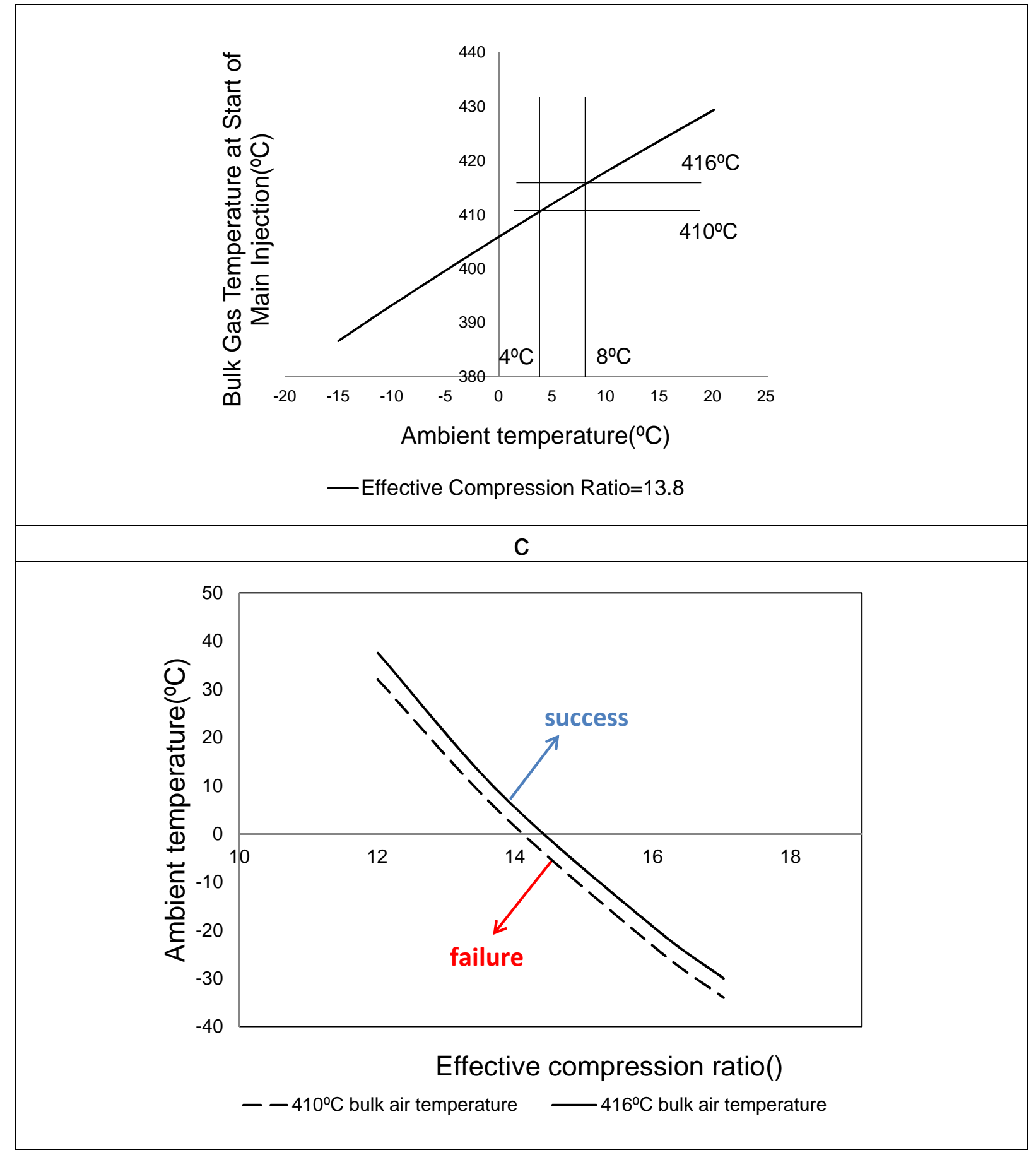

Figure 3: Threshold ambient temperatures for successful combustion over various compression ratios

\section{Optical Studies of Combustion Initiation in a Combustion Bomb}

The initiation and early development of combustion which occur before the effect on cylinder pressure is measureable is of interest here. The studies of initiation by glow plug were carried out using an unstirred, quiescent combustion bomb. This has optical access through a quartz window giving a view normal to the plate in which the injector and glow plug were mounted. The spacing between the injector and glow plug was the same as in the engine. 
The internal volume of the bomb is roughly cylindrical with a length of $190 \mathrm{~mm}$ and a bore of $100 \mathrm{~mm}$. The experimental facility is shown schematically in Figure 4. The same design of Continental HPCR fuel injection system and fuel injector was used as employed on the engine. The injector was of the piezo-electric type, with 8 nozzle holes. The holes have a diameter of $120 \mu \mathrm{m}$.

The volume of the bomb is large compared to the clearance volume of the engine cylinder, and the bomb is used here only to examine the initial development of combustion which effectively takes place at constant pressure. Prior to fuel injection, air in the bomb is quiescent. Whilst this does not reproduce in-cylinder conditions generally, at the low engine speeds associated with cold start-up and idling, turbulence levels are low and motion in the vicinity of the glow plug just prior to the start of combustion is dictated by the momentum of the fuel sprays, entrainment and mixing.

Bulk air temperature and pressure inside the bomb, the internal tip temperature of glow plug and injection parameters such as injection separation, timing and number of injections were controlled and recorded using National Instruments USB-6351 X Series Data Acquisition hardware and Labview software. Rail pressure was monitored by a pressure sensor on the fuel rail; a pressure control valve (PCV) was utilized to adjust pressure in the high pressure fuel pump by means of PID control. Three Watlow cartridge heaters with closed loop temperature control were used to heat the air in the combustion bomb. Each cartridge heater provided $350 \mathrm{~W}$ of heat input. This allowed the bulk air temperature to be raised to a maximum of just over $200^{\circ} \mathrm{C}$. The air temperature close to the glow plug tip was measured separately with a K-type thermocouple which could be withdrawn as required to avoid affecting the initiation process.

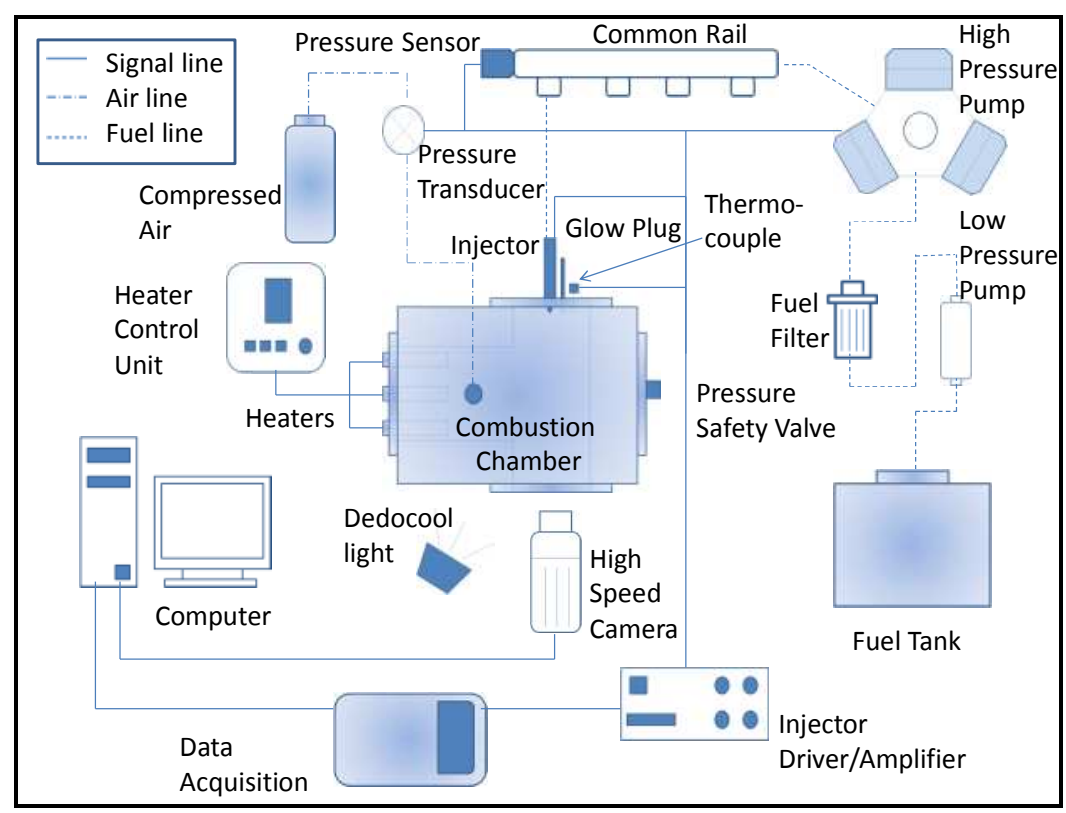




\section{Figure 4: Schematic of the rig architecture}

The glow plug was a non-standard component supplied by Beru for the research; the glow plug was a ceramic design with a $3.3 \mathrm{~mm}$ diameter tip and an embedded R-type thermocouple. Power supply to the glow plug was regulated to achieve a target internal temperature; the surface temperature was related to this internal temperature through calibration experiments conducted separately in quiescent air with a thermocouple in good contact with the surface. Typically the surface temperature was about $100^{\circ} \mathrm{C}$ lower than the core temperature of the glow plug. The relative positions of the glow plug and the injector are shown in Figure 5. The injector could be rotated through a small angle to vary the distance between the glow plug surface and the two adjacent fuel sprays. The distance between the visible edge of the nearest fuel spray and the glow plug tip was determined from a CAD model of the installation and verified by the analysis of video images.

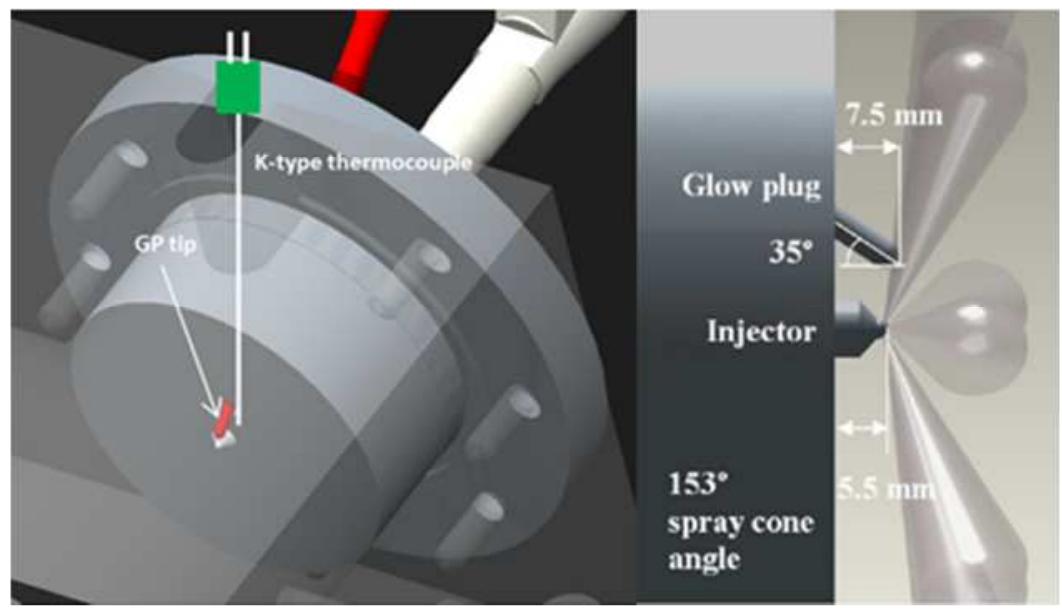

Figure 5: Air temperature measurement near glow plug; Injector spray and glow plug configuration

\section{High Speed Video Records of Luminous Emissions}

High speed video recordings were made of the fuel sprays penetrating the chamber and, if initiation was successful, the first appearance and growth of luminous emissions in one or both sprays adjacent to the glow plug. The camera used was a Phantom V12.1 CMOS high speed camera capable of 6,242 frames per second at a maximum resolution of $1280 \times 800$ pixels. The settings of focal length, aperture and exposure time were respectively $105 \mathrm{~mm}$, $\mathrm{f} / 3.5$ and $100 \mu \mathrm{s}$. One Dedocool tungsten light was used to illuminate the fuel sprays. The settings and ranges of parameters varied during the experiments are summarised in Table 2. A fixed fuel injection strategy of single pilot and main was used throughout the set of experiments; this was different to the injection strategy used in the engine tests. Three parameters were varied, these were bulk air temperature, glow plug temperature and the distance between the glow plug surface and the visible boundary of the nearest spray. The 
first luminous emissions have been taken to indicate the start and site of combustion, as suggested in $[10,19,27]$. The subsequent growth of the luminous area has been taken to indicate successful ignition.

An example of a sequence of images illustrating the successful initiation of combustion is given in Figure 6 for the baseline conditions summarised in Table 2. The first spots of luminous emissions appear close to the glow plug tip at the edge of the fuel spray after the start of the main injection. This local initiation triggers a rapid expansion of the enflamed volume, principally in the downstream direction of spray penetration. There were no significant differences in the way a successful initiation and subsequent development took place when bulk air or glow plug temperature was increased, or distance from glow plug surface to spray edge decreased, from settings at which initiation failed. Once luminous emissions were observed, a successful development always followed. No extinction events were observed.

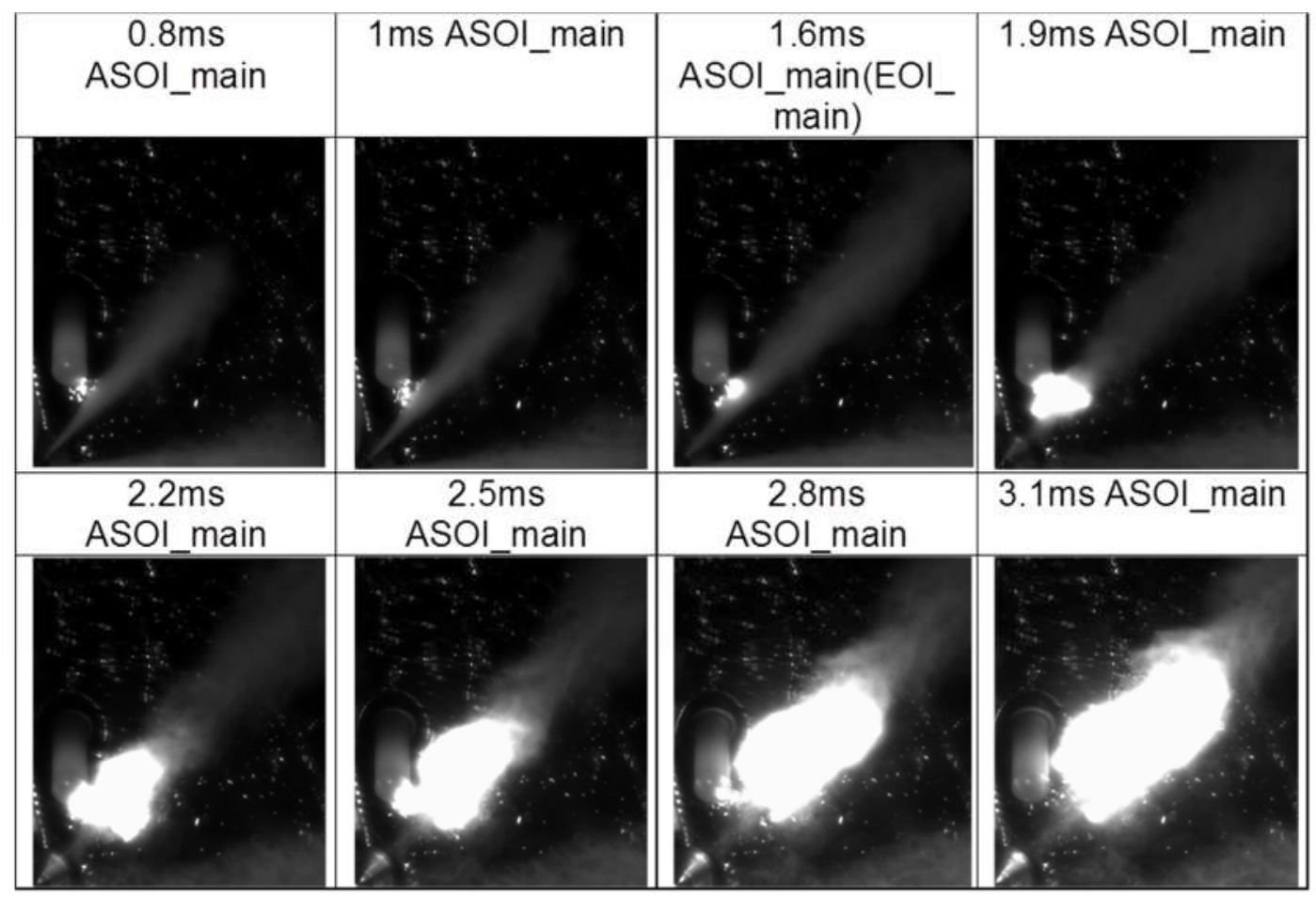

Figure 6: Initiation and development of combustion of a spray in a quiescent bomb using a glow plug. Test condition is referred to baseline condition expressed in Table 2

\section{Initiation Success and Failure Boundaries}

The influence of glow plug temperature on the success or failure of ignition depends on the distance between the glow plug surface and the visible boundary of the spray. The success and failure boundaries have been mapped for two bulk gas temperatures, $200^{\circ} \mathrm{C}$ and $160^{\circ} \mathrm{C}$. 
The results are presented in Figure 7(a) and Figure 7(b) respectively. In all of these cases, the bulk pressure, fuel quantity and injection strategy were fixed at the baseline values given in Table 2. The distance between the glow plug surface and spray edge was varied in steps from zero to the point at which ignition always failed at the highest value of glow plug temperature. The distance was varied by rotating the injector. A deflector plate was used to divert the second adjacent spray away from the glow plug to prevent the ignition of this. For each position of the injector the glow plug temperature was swept from $300^{\circ} \mathrm{C}$ to $1100^{\circ} \mathrm{C}$. Three tests were carried out at each setting. Triangles mark settings at which combustion initiation was always successful. Crosses mark settings at which initiation always failed. Triangle-cross overlapping points represent settings at which both successes and failures were recorded.

Table 2: Summary of test parameter settings

\begin{tabular}{|c|c|c|}
\hline Parameter & Base line & Sweep range \\
\hline $\begin{array}{l}\text { Vessel pressure } \\
\text { (bar) }\end{array}$ & 38 & - \\
\hline Rail pressure(bar) & 400 & - \\
\hline Pilot quantity(mg) & 2 & - \\
\hline $\begin{array}{l}\text { Pilot } \\
\text { quantity(mg/spray) }\end{array}$ & 0.25 & - \\
\hline Main quantity(mg) & 18 & - \\
\hline $\begin{array}{l}\text { Main } \\
\text { quantity(mg/spray) }\end{array}$ & 2.25 & - \\
\hline $\begin{array}{l}\text { Pilot to main } \\
\text { separation(ms) } \\
\text {-SOI(pilot)-SOI(main) }\end{array}$ & 1.7 & - \\
\hline $\begin{array}{l}\text { Bulk air } \\
\text { temperature }\left({ }^{\circ} \mathrm{C}\right)\end{array}$ & 200 & $20-200$ \\
\hline $\begin{array}{l}\text { Glow plug surface } \\
\text { temperature }\left({ }^{\circ} \mathrm{C}\right)\end{array}$ & 900 & $300-1100$ \\
\hline $\begin{array}{l}\text { Glow plug to spray } \\
\text { edge distance(mm) }\end{array}$ & 1.3 & $0-2.6$ \\
\hline
\end{tabular}

As shown in Figure 7 (a) and Figure 7 (b), the surface temperature of the glow plug required for successful ignition rises with increasing separation between the glow plug and the spray edge. The required temperature is lowest when the spray passes close to the surface, but is never less than a minimum value of $413^{\circ} \mathrm{C}$. The same minimum was required for bulk gas temperatures of $200^{\circ} \mathrm{C}$ and $160^{\circ} \mathrm{C}$. The minimum is consistent with the engine test data reported earlier, which indicated a similar temperature of about $413^{\circ} \mathrm{C}$ is required for auto ignition without the aid of the glow plug. In the combustion bomb experiments, the bulk charge temperature could not be pre-heated above $200^{\circ} \mathrm{C}$, and the surface temperature of the glow plug was the controlling minimum. The bulk gas temperature did influence the 
surface temperature required for success at greater separations between glow plug and spray. This can be seen in Figure 7 (c); the required minimum temperature of the glow plug is higher at the lower bulk gas temperature at any given separation distance. This is indicative of the influence of bulk gas temperature on the temperature variation in the region near the glow plug and the need for a minimum temperature of $413^{\circ} \mathrm{C}$ at the site of ignition, which occurs further from the glow plug when glow plug to spray edge separation is greater.

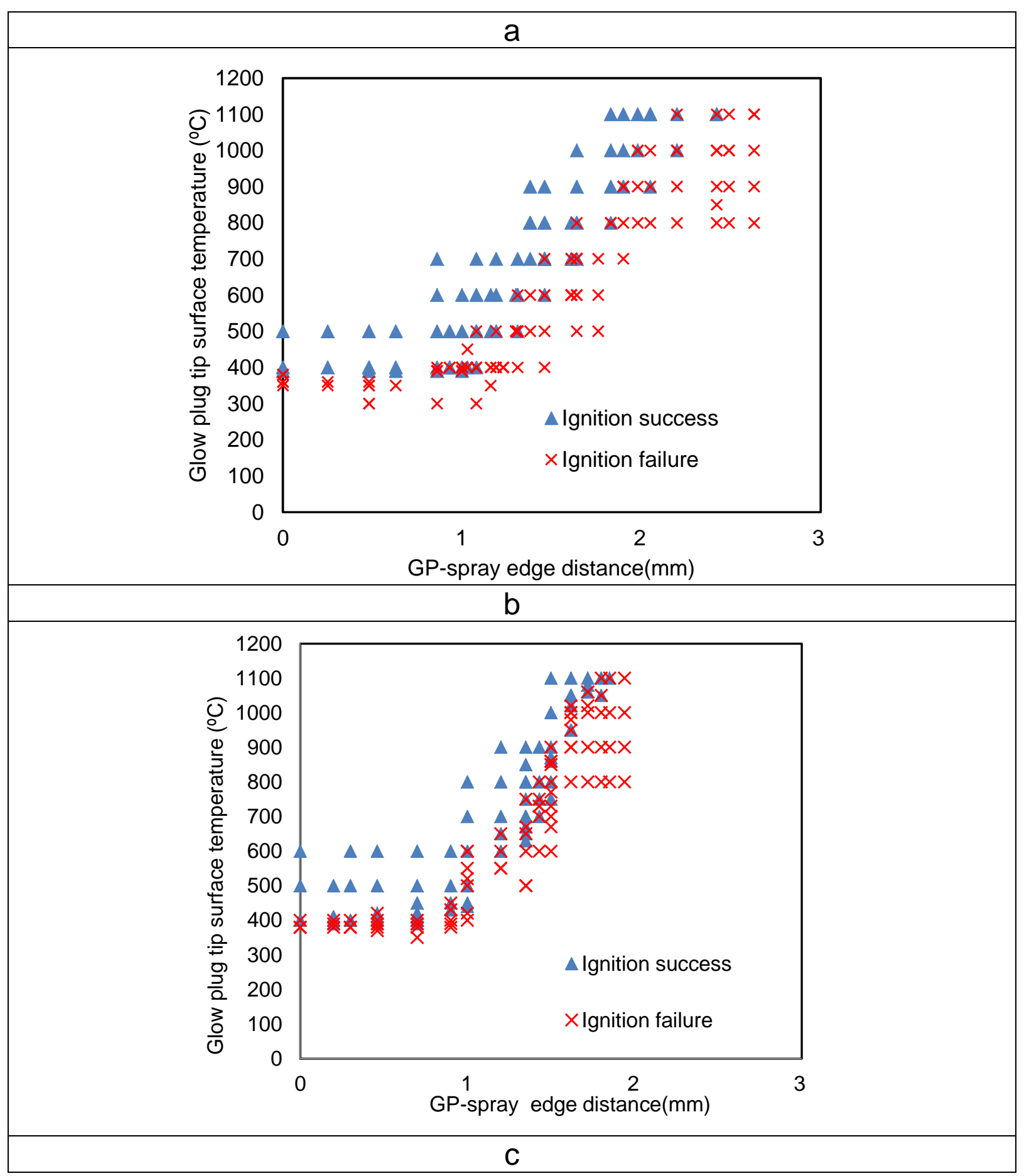




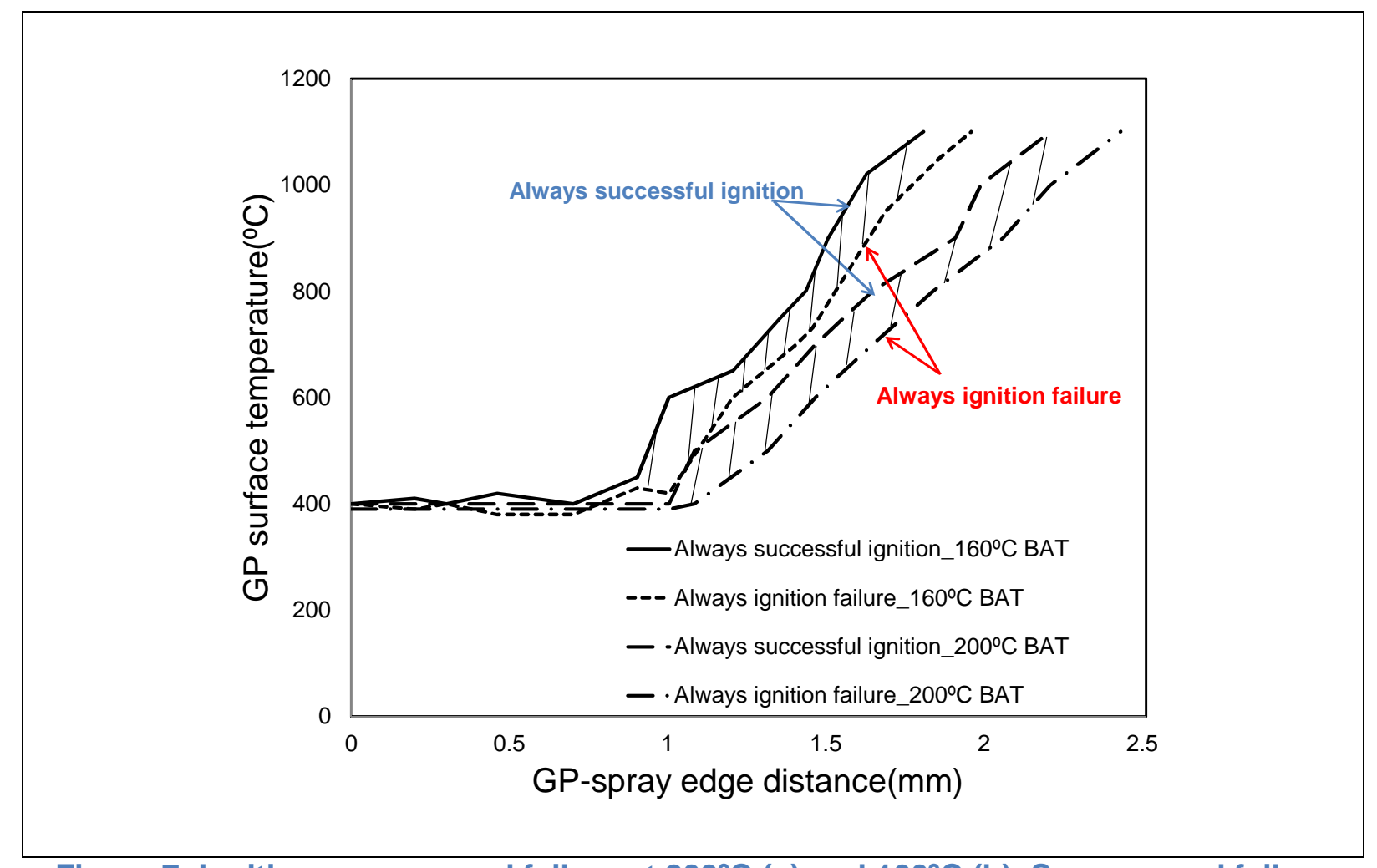

Figure 7: Ignition success and failure at $200^{\circ} \mathrm{C}$ (a) and $160^{\circ} \mathrm{C}$ (b). Success and failure boundary (c)

The influence of bulk gas temperature on the glow plug temperature required for ignition success is shown in Figure 8 for an extended range of gas temperatures, from $20^{\circ} \mathrm{C}$ to $200^{\circ} \mathrm{C}$, and a fixed glow plug to spray separation of $1.3 \mathrm{~mm}$. The results show a progressive reduction in the required glow plug temperature as the bulk gas temperature is raised. As before, three tests were performed per each data point and triangle, cross represents combustion success and combustion failure respectively. The band of glow plug temperatures spanning $100 \%$ failures to $100 \%$ successes is similar across the range of gas temperatures, at $\sim 50^{\circ} \mathrm{C}$. The influence of increasing bulk gas temperature is attributed to improved droplet vaporisation and the extension of the $413^{\circ} \mathrm{C}$ isotherm further towards the spray edge. 


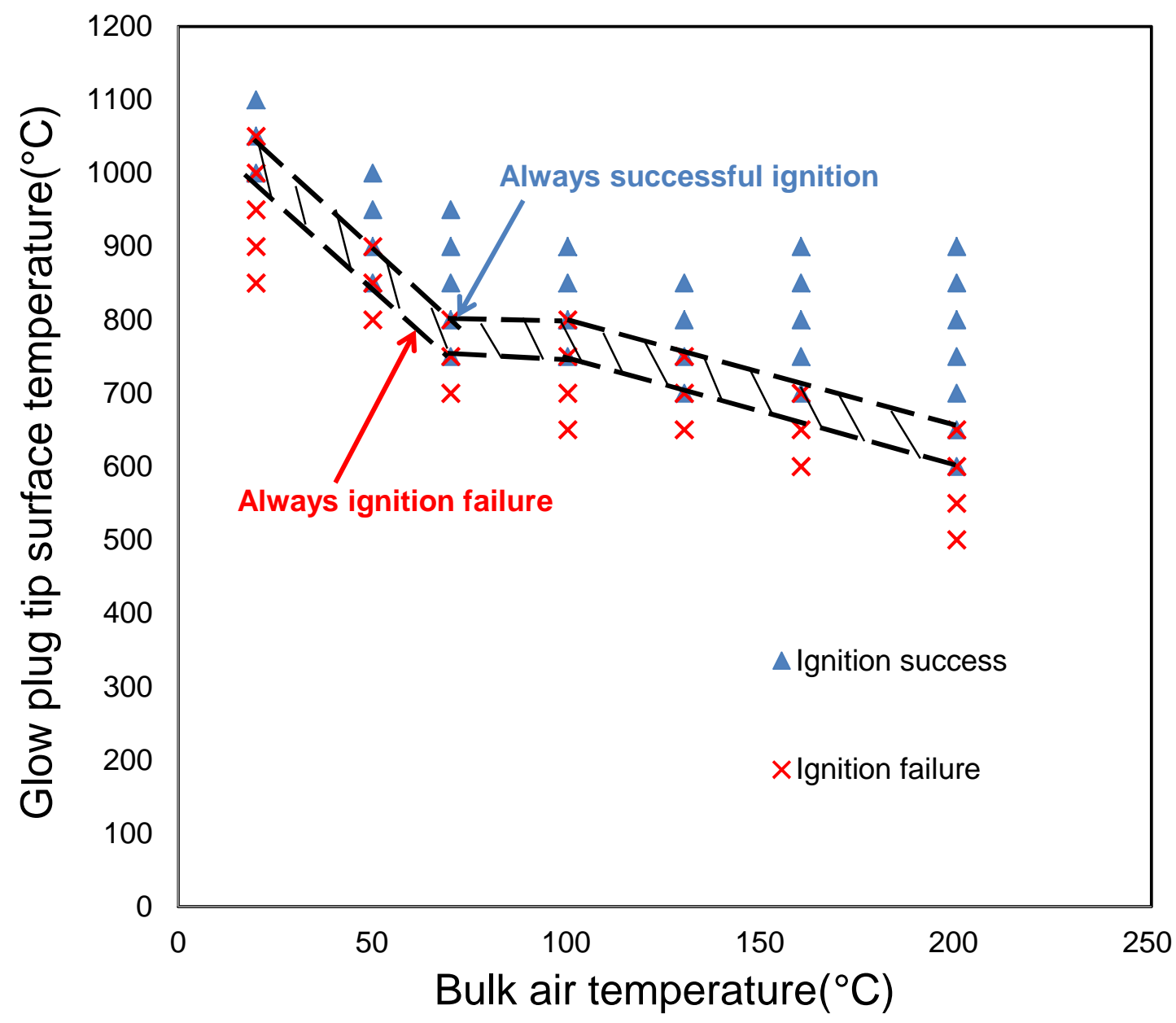

Figure 8: Glow plug surface temperature against bulk air temperature in terms of combustion initiation success and failure in optical combustion bomb

\section{Local Equivalence Ratio}

A limitation of both the engine and the optical studies is that these gave no direct information on the equivalence ratio at the site and time of combustion initiation. As illustrated in Figure 9, however, it can be observed that the site of initiation maintains its proximity to the edge of the spray as the distance between the glow plug and the spray is varied. This suggests that a local minimum equivalence ratio as well as a minimum temperature is required for successful initiation. To explore what the required value of the minimum equivalence ratio is, the CFD code ANSYS Fluent 14.0 has been used to simulate fuel injection, vaporization and mixing of the fuel spray in the vicinity of the glow plug. A cylindrical rod with the same diameter and length as the glow plug tip having a high surface temperature was modelled to represent the glow plug in this setup. The spray was assumed to penetrate into quiescent air at a uniform temperature. The mesh is displayed in Figure 10, a rectangular mesh structure 
containing 178944 cells were made. Minimum orthogonal quality is 0.47 , orthogonal quality larger than 0.2 is considered to be good mesh quality [28]. Further refinement of grid size has been carried out and showed negligible change in results.

Sub-models used in this study are standard options in Fluent 14.0 and have been used without modification. A summary is given in Table 3. The spray has a half cone angle of 8 degrees. The discrete phase model was used to provide stochastic tracking of individual droplets in the Lagrangian approach. The droplet size and spread parameter following the spray primary break up were described by the Rosin-Rammler distribution [29]. Secondary breakup was described by the WAVE breakup model widely used to model high speed diesel injection [29-32]. Parameter B1 dictates the period for particle breakup, influencing spray tip penetration; a value of 20 was determined to give a satisfactory spray tip penetration compared with experimental observations. The dynamic drag model was used to account for the effects of droplet distortion due to aerodynamic forces by linearly varying the drag between that of a sphere and a disc [33]. Discrete random walk model was utilized to predict the dispersion of droplets due to turbulence in the fluid phase. Convection/diffusion controlled model was used following the work of Miller [34] and Sazhin [35] for droplet evaporation considering convective flow of the evaporating material from the droplet surface to the bulk gas phase (Stefan Flow). The standard k-e model was adopted to characterize turbulence in this case. $\mathrm{C}_{10} \mathrm{H}_{22}$ was used to represent light diesel fuel [36, 37].

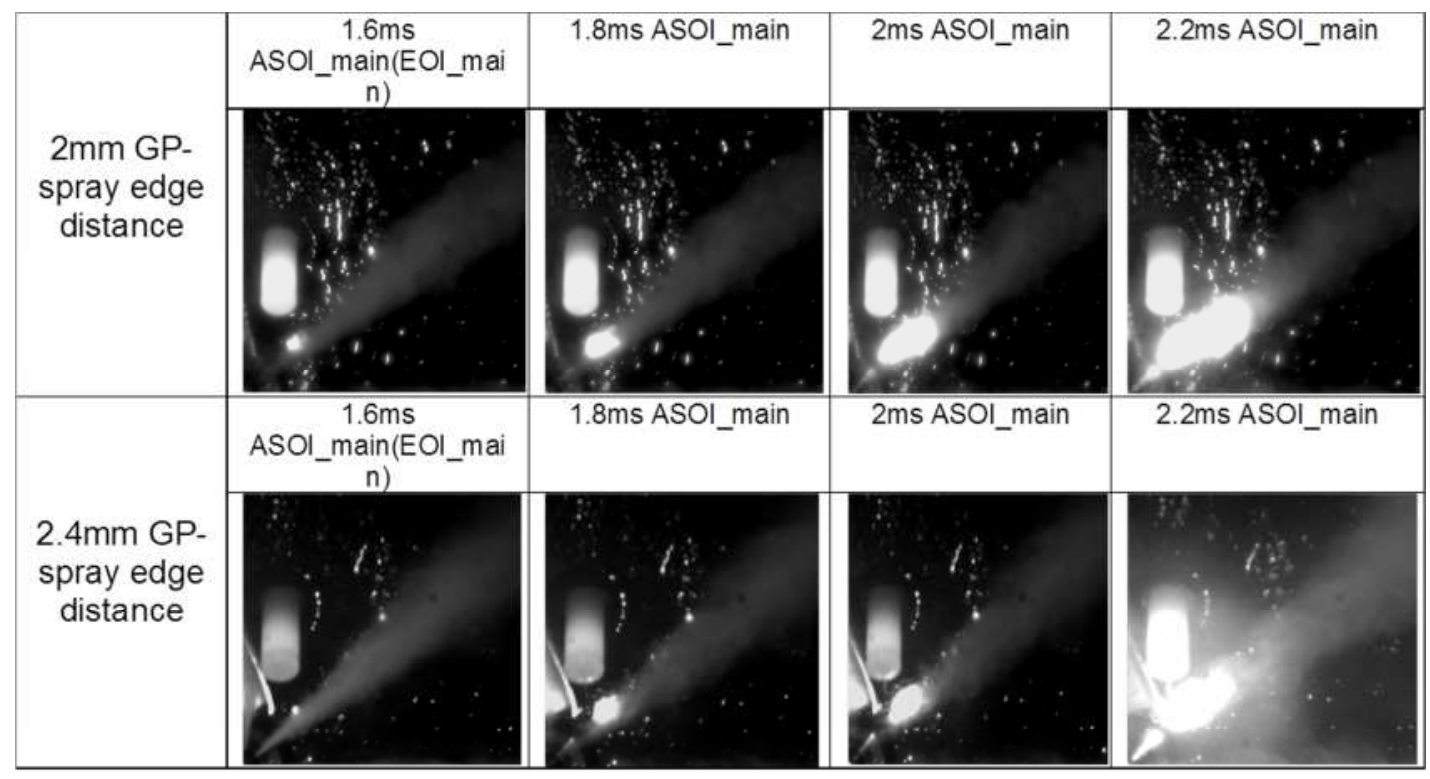

Figure 9: Images showing the site of initial luminous emissions occurs close to the edge of the fuel spray as separation between the spray and the glow plug is increased from $1.3 \mathrm{~mm}$ in Figure 6 to $2.0 \mathrm{~mm}$ (upper images) and $2.4 \mathrm{~mm}$ (lower images), with a glow plug temperature setting of $1100^{\circ} \mathrm{C}$ 


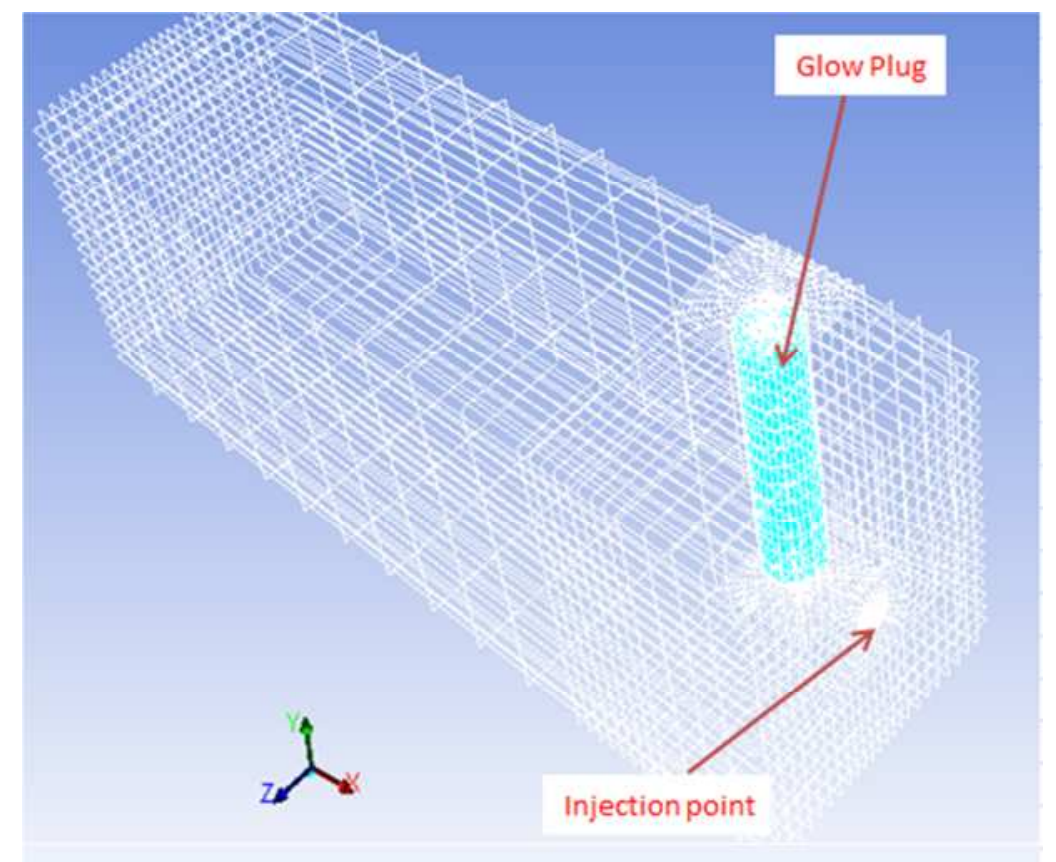

Figure 10: Fluent model mesh display

Table 3: Submodels used in CFD prediction

\begin{tabular}{|l|l|l|}
\hline Definition & Models & Comments \\
\hline Fuel Injection model & Solid cone injection model & $\begin{array}{l}\text { The half cone angle was } \\
\text { measured to be 8 degrees in } \\
\text { high speed video recordings. }\end{array}$ \\
\hline Primary breakup model & Rosin-Rammler distribution & $\begin{array}{l}\text { Droplet diameter distribution } \\
\text { produced by primary breakup }\end{array}$ \\
\hline Secondary breakup model & WAVE breakup model & $\begin{array}{l}\text { Describes droplet breakup } \\
\text { induced by the relative velocity } \\
\text { between the gas and liquid } \\
\text { phases. Model coefficient } \\
\text { B1=20 }\end{array}$ \\
\hline Droplet drag model & Dynamic drag model & To determine drag coefficient \\
\hline $\begin{array}{l}\text { Turbulent dispersion } \\
\text { model }\end{array}$ & Discrete random walk model & $\begin{array}{l}\text { To track particle motion } \\
\text { influenced by turbulence }\end{array}$ \\
\hline Droplet evaporation model & $\begin{array}{l}\text { Convection/diffusion controlled } \\
\text { evaporation model }\end{array}$ & $\begin{array}{l}\text { Stefan flow effect has been } \\
\text { taken into account }\end{array}$ \\
\hline Turbulence model & Standard k-e model & $\begin{array}{l}\text { Single component hydrocarbon } \\
\text { model used to represent light } \\
\text { diesel }\end{array}$ \\
\hline Diesel fuel & C10H22 & \\
\hline
\end{tabular}

Simulations were carried out for bulk air temperatures of $200^{\circ} \mathrm{C}$ and $160^{\circ} \mathrm{C}$, from the start of pilot injection to the time when the first luminous emissions were observed in the experimental work, or later for cases when ignition failed. For each case, the spatial variation of vapour air equivalence ratio in the vicinity of the $413^{\circ} \mathrm{C}$ isotherm surrounding the glow plug was predicted for the time when the first luminous soot emission appeared. Various combinations of glow plug temperature, bulk air temperature and separation between glow plug and spray edge were covered. The ignition success and failure boundaries mapped 
from the experimental results are shown in Figure 7 (c). The corresponding predictions of fuel air equivalence ratio at the $413^{\circ} \mathrm{C}$ isotherm are given in Figure 11. Along the boundary between ignition always failing and sometimes succeeding, the computational results show that fuel air equivalence ratio at the $413^{\circ} \mathrm{C}$ isotherm is approximately 0.15 . Along the boundary between ignition sometimes failing and always succeeding, the predicted fuel air equivalence ratio at the $413^{\circ} \mathrm{C}$ isotherm is approximately 0.35 . The lower and upper values of equivalence ratio between which ignition could fail or succeed did not vary with glow plug temperature, bulk air temperature or separation between glow plug and spray edge.

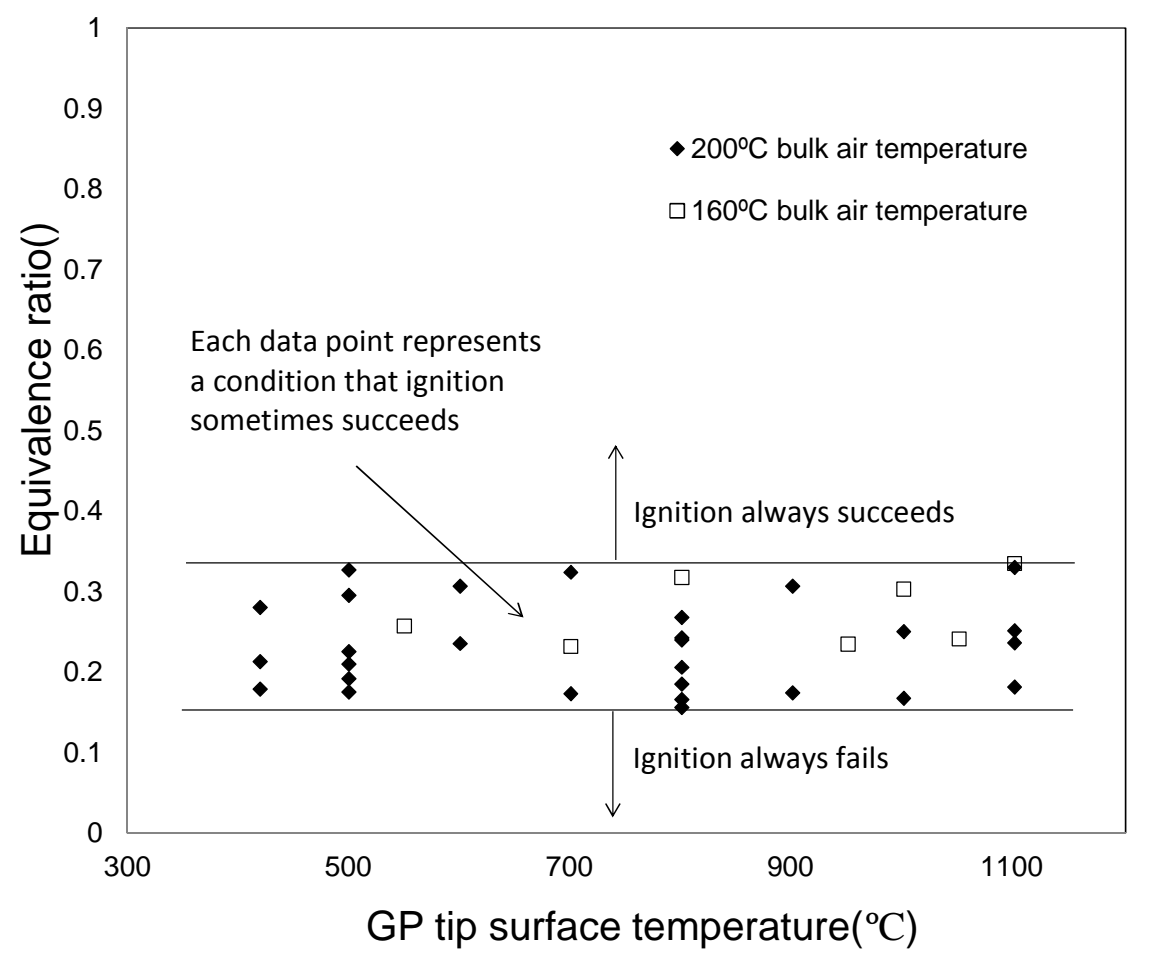




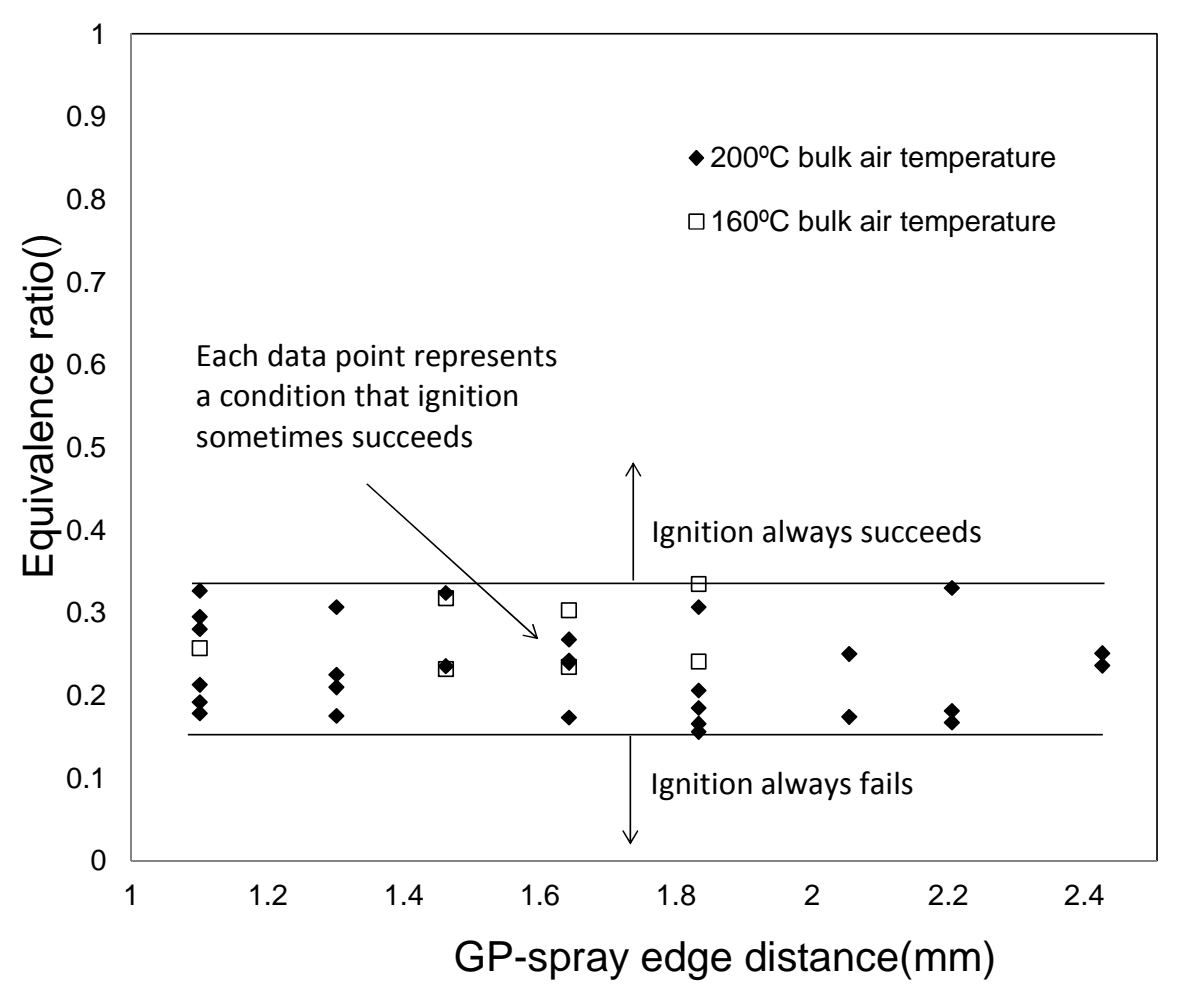

Figure 11: Equivalence ratio at $413^{\circ} \mathrm{C}$ isotherm at appearance time of the first luminous soot emission for points in shaded area shown in Figure 7 (c)

\section{Discussion}

Combustion initiation is the combined effect of physical mixture preparation and chemical processes. Mixture preparation progresses from the break up and atomisation of the fuel jet, to the vaporisation of droplets, the mixing of vapour and air and mixture diffusion towards glow plug tip. Pacaud [7] carried out a computational study of the auto-ignition mechanism using $n$-heptane to represent diesel. They concluded that the lowest temperature required to achieve auto-ignition of diesel under cold start conditions without the aid of a glow plug was $660 \mathrm{~K}\left(387^{\circ} \mathrm{C}\right)$. This is low compared to the value of $413^{\circ} \mathrm{C}$ determined in the current work, which is close to the value of $415^{\circ} \mathrm{C}$ determined by Broatch et al. [21] following a similar experimental approach. It is also closer to the temperature of $700 \mathrm{~K}\left(427^{\circ} \mathrm{C}\right)$ reported in [27] to be required for hydrocarbons to undergo $\beta$-scission to form olefins and stabilized alkyl radicals like $\mathrm{CH}_{3}$ that can be oxygenated by $\mathrm{OH}$ radicals.

The tests performed in this study indicate self- sustaining reactions can be initiated at bulk charge temperatures above $413^{\circ} \mathrm{C}$ to form a local exothermic site which grows to enflame the mixture produced by the main injection. At lower bulk temperatures, the assistance of the glow plug is required as illustrated in Figure 12 to create a zone with a $413^{\circ} \mathrm{C}$ isotherm 
boundary close to the edge of the fuel spray. The position of the boundary is determined by the glow plug surface temperature and the bulk air temperature. The bulk temperature and temperature field around the glow plug also affects equivalence ratio by promoting vaporization, and the glow plug-spray proximity determines the amount of generated vapour allocated inside the reacting zone. For the fixed fuel rail pressure and injection strategy used, the equivalence ratio should be at least 0.15 in this zone for a self-sustaining reaction. Changing either rail pressure or injection strategy will influence mixture preparation and the evolution of equivalence ratio near the glow plug. In turn this will influence ignition delay and the development of combustion $[19,38]$. The effect on the minimum equivalence ratio requirement is more uncertain, but does not change the need for a minimum local heat release per unit volume to establish a self-sustaining reaction. Using the Arrhenius-type correlation presented by Assanis [39], the predicted ignition delay at a temperature, pressure and equivalence ratio of $413^{\circ} \mathrm{C}, 38$ bar and 0.35 , respectively, was $1.5 \mathrm{~ms}$. This is equivalent to $9^{\circ} \mathrm{CA}$ at an engine speed of $1000 \mathrm{rpm}$ and consistent with the ignition delay observed in the engine test results illustrated in Figure 1.

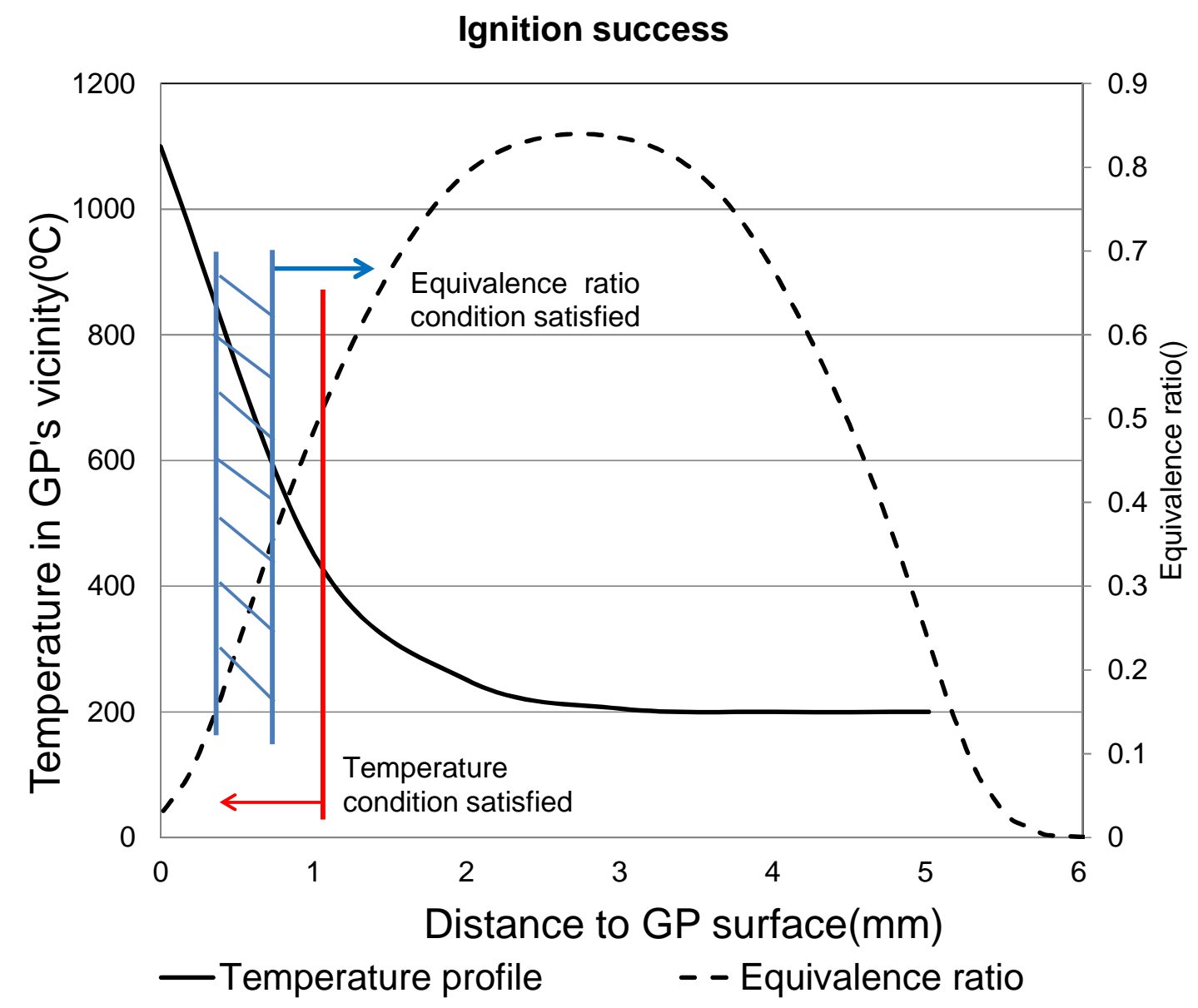

Figure 12: Illustration of combustion initiation mechanism 
In Figure 13, from engine test data, the variation of net heat release and the corresponding injector drive signals are plotted against crank angle for a typical early firing cycle produced with a single pilot and main injection strategy. In the same figure, images from the combustion bomb experiments using the same single pilot and main strategy are shown and linked to the corresponding points in the heat release data. The information from these complementary sources aids understanding of the stages the initiation and development process goes through. As illustrated by Figure 13, when a single-pilot-plus-main injection strategy is used, the pilot injection generates a region of premixed fuel vapour and air near the glow plug without producing any luminous emissions prior to the start of the main injection. Soot emissions first appear only after the main injection raises the local equivalence ratio above the required threshold. In the case illustrated, the glow plug is equally-distant from the two nearest fuel sprays and luminous emissions appear at the edges of both sprays. The momentum and mixing of the main spray can displace and distort the luminous area before inflammation expands downstream in both sprays adjacent to the glow plug. The heat release rate rises rapidly and is strongly influenced by the pilot injection strategy. Using two pilot injections, as in the cases presented in Figure 1, heat release displays a clear first peak. In Figure 13, the first peak is less prominent. The magnitude of the peak strongly suggests combustion has already spread to the injector's other sprays. After the first peak, the heat release rate can dip or flattens before increasing to a second peak associated with mixing controlled combustion. 


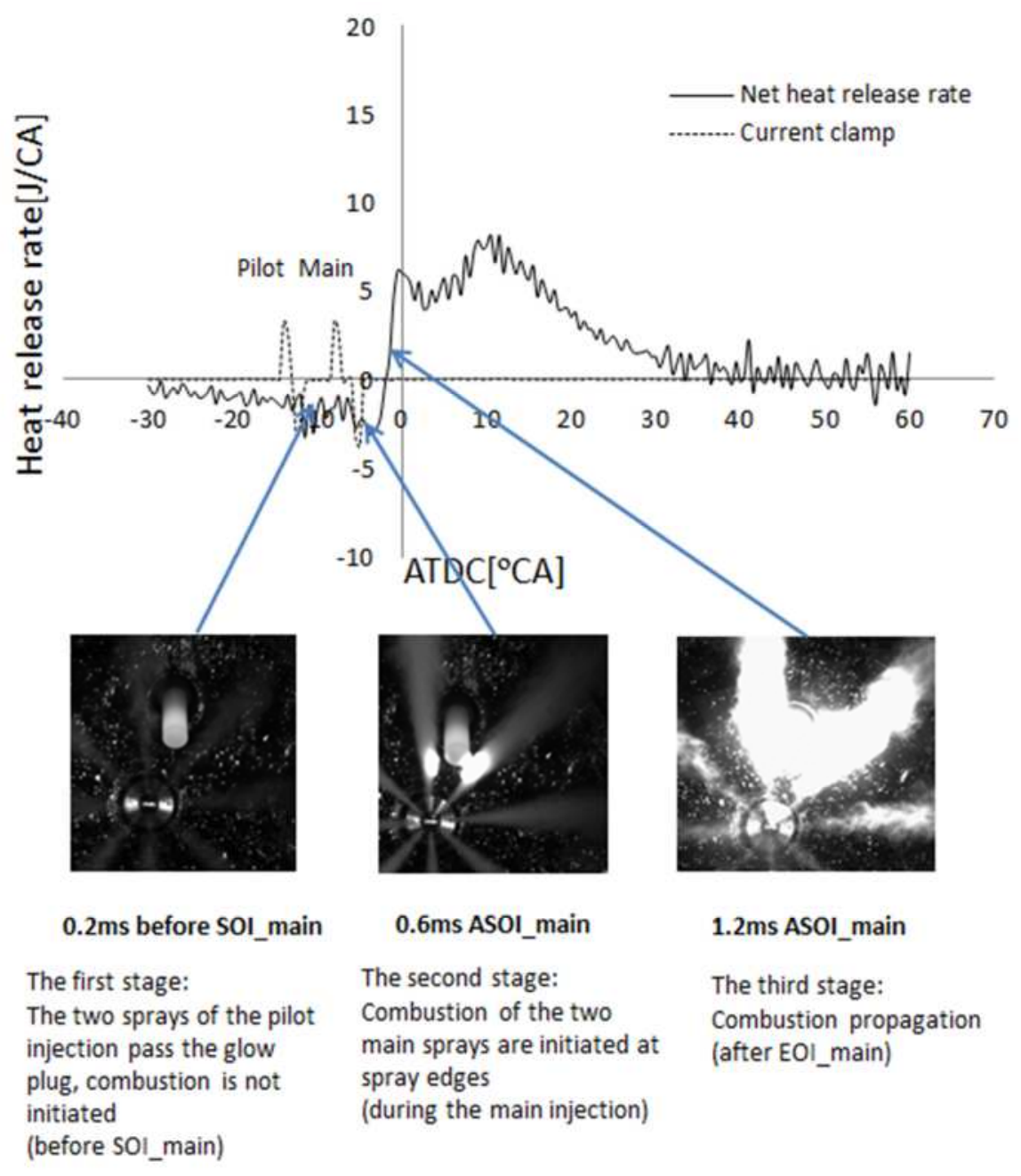

Figure 13: Net heat release rate, injection pulse as a function of crank angle after TDC, Images showing combustion events at corresponding time with engine operation. Engine test condition: $850^{\circ} \mathrm{C}$ glow plug temperature, rail pressure: $400 \mathrm{bar}$, soak temperature: $10^{\circ} \mathrm{C}$, injection quantity: $(2,7) \mathrm{mg}$, engine speed: 1000r/min, injection timing: $(-14,-8)^{\circ} \mathrm{CA}$ ATDC

A similar compilation of images for an injection strategy comprised of two pilot injections and a main injection is shown in Figure 14. Again, the first pilot injection does not initiate combustion but generates a premixed region near to the glow plug. The first luminous emissions appear after the second pilot injection. The luminous area grows locally and aids the development of combustion when the main injection takes place. Compared to the heat release rate from the single pilot strategy, a stronger premixed spike is observed followed by a more vigorous mixing controlled combustion. Previous work [10, 22], has shown that both work output and cold idling stability are improved by increasing the number of pilots from one to two, even if the total pilot fuelling is the same. 


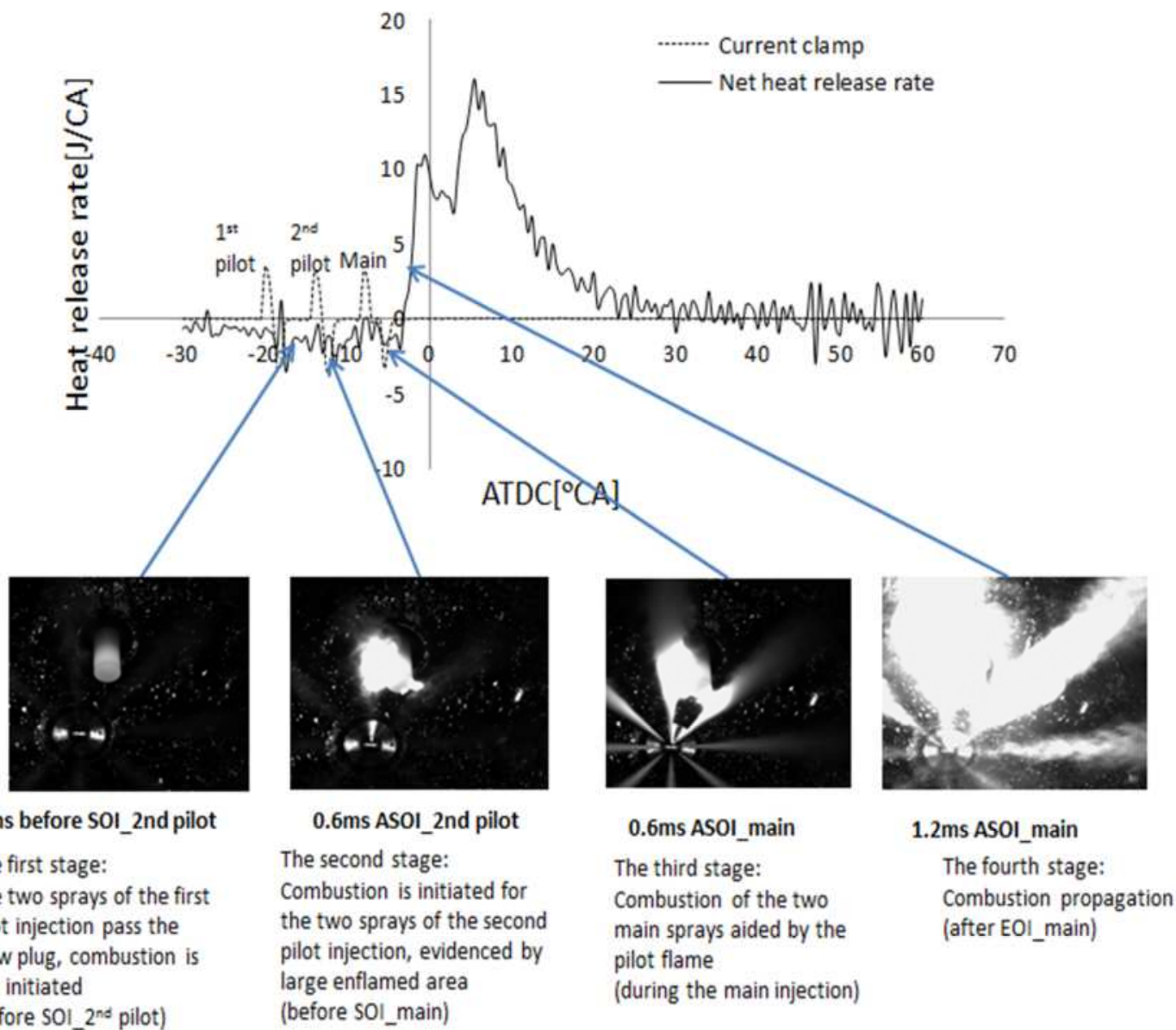

Figure 14: Net heat release rate, injection pulse as a function of crank angle after TDC, Images showing combustion events at corresponding time with engine operation. Engine test condition: $850^{\circ} \mathrm{C}$ glow plug temperature, rail pressure: 400 bar, soak temperature: $10^{\circ} \mathrm{C}$, injection quantity: $(2,2,5) \mathrm{mg}$, engine speed: 1000r/min, injection timing: $(-20,-14,-8)^{\circ} \mathrm{CA}$ ATDC

In addition to meeting the temperature requirement for initiation, the glow plug must contribute to fuel vaporisation at the edge of the injector spray to meet the equivalence ratio requirement and promote the rapid development of the subsequent heat release. In the example illustrated, the bulk air temperature in the combustion bomb was $200^{\circ} \mathrm{C}$, lower than the temperature in the engine cylinder at the start of injection which Figure 3(b) indicates would be about $418^{\circ} \mathrm{C}$, for a $10^{\circ} \mathrm{C}$ ambient condition. At a bulk temperature of $418^{\circ} \mathrm{C}$, the initiation can be achieved without the aid of the glow plug. However, as indicated in Figure 1, without the glow plug on, the heat release rises slowly even with a twin pilot strategy. The assistance of the glow plug raises the cummulative heat release and reduces the cycle by cycle variations in work output up to ambient temperatures of around $20{ }^{\circ} \mathrm{C}$, for which the bulk gas temperature at the time of injection is $\sim 430^{\circ} \mathrm{C}$. The continuing advantage of using the glow plug must be associated with improved vaporisation of the spray, strengthening the early development of combustion before high heat release rates are achieved. When the bulk temperature is $\sim 430{ }^{\circ} \mathrm{C}$ or higher, vaporisation of the spray occurs quickly enough to 
make the glow plug redundant. It should be noted, however, that these observations are general in character but may vary in detail with changes in injection strategy. The data presented is limited to specific injection stratgies and in previous work[1, 2], it has been shown that both glow plug temperature and injection strategy have a strong influence on cold idling performance.

\section{Conclusions}

A fixed injection strategy, fuel rail pressure and fuel type were used throughout the set of engine tests reported. The effects of varying these on mixture preparation and combustion initiation have not been examined. The hardware and settings are typical of modern light duty automotive engines and settings for cold idling, rather than comprehensive. Subject to the uncertainty associated with these limitations, the following conclusions are drawn. .

Two necessary and sufficient conditions for the successful initiation and development of combustion have been identified. At the site of initiation the temperature must be above $413^{\circ} \mathrm{C}$ and the vapour air equivalence ratio must be at least 0.15 to 0.35 .

The main role of the glow plug is to raise local temperature to at least $413^{\circ} \mathrm{C}$. Its second role is to promoting vapour generation early in the mixture preparation process. This is important both to meeting the minimum equivalence ratio requirement and to the subsequent rapid development of heat release.

The glow plug improves combustion characteristics at ambient temperatures higher than those requiring the glow plug for initiation of combustion. In the current work, fuel utilization and cycle by cycle stability were improved up to ambient temperatures of $20^{\circ} \mathrm{C}$. Beyond this, the glow plug gave no improvement over initiation by autoignition.

\section{Reference}

[1] McGhee, M.J., Shayler, P. J., La Rocca, A., Murphy, M., Pegg, I, The Influence of Injection Strategy and Glow Plug Temperature on Cycle by Cycle Stability Under Cold Idling Conditions for a Low Compression Ratio, HPCR Diesel Engine. SAE International Journal of Engines, 2012. 5(3): p. 923-937.

[2] McGhee, M.J., Shayler, P. J., La Rocca, A., Murphy, M., Pegg, I, Investigations of Injection Strategies for Stable Cold Idling of an HPCR Diesel Engine with a Compression Ratio of 15.5:1, in IMechE Conference C1342 Fuel Systems for IC Engines. 2012: London.

[3] Weilenmann, M., Favez, J., Alvarez, R, Cold-start emissions of modern passenger cars at different low ambient temperatures and their evolution over vehicle legislation categories. Atmospheric Environment, 2009. 43(15): p. 2419-2429. 
[4] Bielaczyc, P., Merkisz, J., Pielecha, J, Investigation of exhaust emissions from DI diesel engine during cold and warm start. SAE paper 2001-01-1260, 2001.

[5] Bielaczyc, P., Merkisz, J., Pielecha, J, A method of reducing the exhaust emissions from DI diesel engines by the introduction of a fuel cut off system during cold start. SAE paper 200101-3283, 2001.

[6] MacMillan, D., La Rocca, A., Shayler, P. J., Murphy, M., Pegg, I.G, The effect of reducing compression ratio on the work output and heat release characteristics of a DI diesel under cold start conditions. SAE Paper 2008-01-1306, 2008.

[7] Pacaud, P., Perrin, H., Laget, O, Cold start on diesel engine: Is low compression ratio compatible with cold start requirements? SAE Paper 2008-01-1310, 2008.

[8] Cursente, V., Pacaud, P., Gatellier, B, Reduction of the Compression Ratio on a HSDI Diesel Engine: Combustion Design Evolution for Compliance the Future Emission Standards. SAE Paper 2008-01-0839, 2008.

[9] Beatrice, C., Avolio, G., Giacomo, N.D., Guido, C, Compression Ratio Influence on the Performance of an Advanced Single-Cylinder Diesel Engine Operating in Conventional and Low Temperature Combustion Mode. SAE Paper 2008-01-1678, 2008.

[10] McGhee, M., in Factors Influencing Cycle-by-Cycle Combustion Characteristics of a Diesel Engine under Cold Idling Conditions. PhD thesis, 2012, University of Nottingham.

[11] http://www.mazda.co.uk/aboutmazda/skyactiv-technology/. Accessed October 2014.

[12] Kern, C., Dressler, W., Lindemann, G., Rothacker, V, An innovative glow system for modern diesel engines. SAE paper 1999-01-1240, 1999.

[13] Payri, F., Broatch, A., Serrano, J.R., Rodríguez, L.F., Esmorís, A, Study of the potential of intake air heating in automotive DI diesel engines. SAE Paper 2006- 01-1233, 2006.

[14] MacMillan, D., Influences on the Cold Start Behaviour of a Diesel Engine at Reduced Compression Ratio. PhD thesis, 2009: University of Nottingham.

[15] Walter, B., Perrin, H., Dumas, J.P, Laget, O, Cold Operation with Optical and Numerical Investigations on a Low Compression Ratio Diesel Engine. SAE Paper 2009-01-2714, 2009.

[16] Chartier, C., Aronsson, U., Andersson, O, Effect of injection strategy on cold start performance in an optical light duty DI diesel engine. SAE paper 2009-24-0045, 2009.

[17] Mueller, C., Musculus, M., Glow Plug Assisted Ignition and Combustion of Methanol in an Optical DI Diesel Engine. SAE Technical Paper 2001-01-2004, 2001.

[18] Pastor, J.V., Bermúdez, V., García-Oliver, J.M., Ramírez-Hernández. J.G, Influence of SprayGlow Plug Configuration on Cold Start Combustion for High-Speed Direct Injection Diesel Engines. Energy, 2011. 36(9): p. 5486-5496.

[19] Pastor, J.V., García-Oliver, J.M., Pastor, J. M., Ramírez-Hernández, J. G, Ignition and combustion development for high speed direct injection diesel engines under low temperature cold start conditions. Fuel, 2011. 90(4): p. 1556-1566.

[20] Imaoka, Y., Nishizawa, T., Lio, S., Hasegawa, M., Teraji, A., Kawamoto, K., Three-dimentional numerical analysis of diesel combustion under cold ambient conditions. International $\mathrm{J}$ of Engine Research, 2015. 16(1): p. 68-80.

[21] Broatch, A., Ruiz, S., Margot, X., Gil, A, Methodology to Estimate the Threshold In-Cylinder Temperature for Self-Ignition of Fuel During Cold Start of Diesel Engines. Energy, 2010. 35: p. 2251-2260.

[22] MacMillan, D., La Rocca, A., Shayler, P.J, Investigating the Effects of Multiple Pilot Injections on Stability at Cold Idle for a DI Diesel Engine. SAE Paper 2009-01-0612, 2009.

[23] MacMillan, D., LaRocca, A., Shayler, P.J., The effect of reducing compression ratio on the work output and heat release characteristcs of a DI diesel engine under cold start conditions. SAE Paper 2008-01-1306, 2008.

[24] Heywood, J.B., Internal Combustion Engine Fundamentals. 1988, New York: McGraw-Hill.

[25] Brunt, M.F., Rai, A., Emtage, A.L, The Calculation of Heat Release Energy from Engine Cylinder Pressure Data. SAE Paper 981052, 1998. 
[26] Brunt, M., Platts, K., Calculation of Heat Release in Direct Injection Diesel Engines. SAE Paper 1999-01-0187, 1999.

[27] Edwards, C.F., Siebers, D. L., and Hoskin, D. H, A Studyof the Autoignition Process of a Diesel Spray via High Speed Visualization. SAE Transactions 1992. 101(3): p. 187-204.

[28] Introduction to ANSYS Meshing: Mesh Quality.

[29] ANSYS Fluent 14.0 Theory Guide.

[30] Bekdemir, C., Numerical Modeling of Diesel Spray Formation and Combustion. Eindhoven University of Technology, Master thesis, 2008.

[31] Mohamed Ismail, H., H.K. Ng, and S. Gan, Evaluation of non-premixed combustion and fuel spray models for in-cylinder diesel engine simulation. Applied Energy, 2012. 90: p. 271-279.

[32] Abbas, G., Kohei, Fukuda., Ram, Balachandar., Ronald, Barron., Numerical Investigation of Spray Characteristics of Diesel Alternative Fuels. SAE International Journal of Engines 201201-1265, 2012.

[33] Liu, A.B., Mather, D., Reitz, R. D., Modeling the Effects of Drop Drag and Breakup on Fuel Sprays. SAE technical Paper 930072, 1993.

[34] Miller, R.S., Harstad, K., Bellan, J. , Evaluation of Equilibrium and Non-Equilibrium Evaporation Models for Many Droplet Gas-Liquid Flow Simulations. International Journal of Multiphase Flow, 1998. 24(6): p. 1025 -1055.

[35] Sazhin, S.S., Kristyadi,T., Abdelghaffar, W.A., Heikal, M.R. , Models for Fuel Droplet Heating and Evaporation: Comparative Analysis. Fuel, 2006. 85: p. 1613-1630.

[36] Guan Jhong, W., Chia Jui,C., Yu Hsuan. S., Yong Yuan, K., CFD Modelling of a Turbo-charged Common-rail Diesel Engine. SAE International, 2013.

[37] Wei, J., Dracos, N., Energy Modeling of Large 2-Stroke Marine Diesel Engine using CFD. Low Carbon Shipping Conference, London, 2013.

[38] Desantes, J.M., Garcia-Oliver, J.M., Pastor, J.M., Ramirez-Hernandez, J.G, Influence of Nozzle Geometry on Ignition and Combustion for High-Speed Direct Injection Diesel Engines under Cold Start Conditions. Fuel, 2011. 90: p. 3359-3368.

[39] Assanis, D.N., Filipi, Z. S., FivelandS. B., Syrimis, M. , A Predictive Ignition Delay Correlation Under Steady-State and Transient Operation of a Direct Injection Diesel Engine. J. Eng. Gas Turbines Power 2003. 125(2): p. 450-457.

\section{Nomenclature}

\begin{tabular}{|ll|}
\hline $\mathrm{P}$ & Pressure \\
$\mathrm{n}$ & Compression polytropic index \\
$\mathrm{V}$ & Volume \\
\multicolumn{3}{|c|}{ Greek } & symbols \\
$\gamma$ & Heat capacity ratio \\
\multicolumn{3}{|c|}{} \\
Abbreviations \\
GP & Glow plug \\
BAT & Bulk air temperature \\
SOI & Start of injection \\
EOI & End of injection \\
ASOI & After start of injection \\
CA & Crank angle \\
\hline
\end{tabular}

